\title{
Viroid: A Useful Model for Studying the Basic Principles of Infection and RNA Biology
}

\author{
Biao Ding, ${ }^{1,2,3}$ and Asuka Itaya ${ }^{1}$ \\ ${ }^{1}$ Department of Plant Cellular and Molecular Biology and Plant Biotechnology Center, ${ }^{2}$ The RNA Group, and ${ }^{3}$ Molecular, \\ Cellular and Developmental Biology Program, Ohio State University, 207 Rightmire Hall, \\ 1060 Carmack Road, Columbus 43210, U.S.A.
}

Submitted 25 April 2006. Accepted 17 July 2006.

\begin{abstract}
Viroids are small, circular, noncoding RNAs that currently are known to infect only plants. They also are the smallest self-replicating genetic units known. Without encoding proteins and requirement for helper viruses, these small RNAs contain all the information necessary to mediate intracellular trafficking and localization, replication, systemic trafficking, and pathogenicity. All or most of these functions likely result from direct interactions between distinct viroid RNA structural motifs and their cognate cellular factors. In this review, we discuss current knowledge of these RNA motifs and cellular factors. An emerging theme is that the structural simplicity, functional versatility, and experimental tractability of viroid RNAs make viroid-host interactions an excellent model to investigate the basic principles of infection and further the general mechanisms of RNA-templated replication, intracellular and intercellular RNA trafficking, and RNA-based regulation of gene expression. We anticipate that significant advances in understanding viroid-host interactions will be achieved through multifaceted secondary and tertiary RNA structural analyses in conjunction with genetic, biochemical, cellular, and molecular tools to characterize the RNA motifs and cellular factors associated with the processes leading to systemic infection.
\end{abstract}

Additional keywords: nucleus, phloem, RNA silencing.

The discovery of Potato spindle tuber viroid (PSTVd) Diener 1971) unearthed a new world of "free" RNA pathogens. Extensive research over the past three decades has firmly established that viroids are the simplest form of RNA-based infectious agents. In contrast to viruses, these small (250 to 400 nucleotides [nt]), single-stranded, circular RNAs do not have proteincoding capacity and are not encapsidated in a protein or membrane shell. Furthermore, unlike other subviral agents such as defective interfering RNAs, satellite RNAs, and satellite viruses (Simon et al. 2004), viroids do not require the presence of helper viruses to establish infections in host plants. Thus, a viroid contains all of the genetic information to mediate replication in single cells and systemic trafficking throughout a plant to establish infection. Furthermore, direct interactions between viroid RNAs and specific cellular components may lead to alterations in host plant developmental processes that exhibit as disease symptoms.

Corresponding author: B. Ding; Telephone: (614) 247-6077; Fax: (614) 292-5379; E-mail: ding.35@osu.edu
A good understanding of viroids and viroid infection is necessary for practical purposes, such as their detection in field crops and control of their spread through quarantine or genetic engineering. However, viroid infection has much more to offer to biologists. It presents a simple model system to address some basic questions about the evolution of RNA-based pathogens, RNA-mediated gene regulation, and RNA structure-function relationships. What are the minimal sequence or structural features that are required to make an RNA infectious? What is the minimal set of proteins that are required to assist such an RNA to establish infection? How could a noncoding and nonencapsidated RNA survive the cellular environment that is armed with all means of surveillance, detection, and destruction of alien RNAs? Even more strikingly, how could cellular machinery recognize such alien RNAs to amplify and then traffic them throughout an organism to spread infection? How do such RNAs interact with cellular factors to alter host development and physiology to produce disease symptoms? What do viroid diseases tell us about the basic regulatory mechanisms of gene expression? Does noncoding RNA-mediated development of diseases occur beyond the viroid world?

We will not address each of these questions in this review because we do not have answers yet for many of the questions. However, we hope to illustrate that elucidating viroid-host interactions can contribute significant knowledge to basic biology, beyond potential agricultural applications. Addressing these questions clearly requires the participation of biologists with diverse and complementary backgrounds and the utilization of multidisciplinary approaches.

For comprehensive information about viroids and viroidhost interactions, readers are referred to recent excellent review articles (Flores et al. 2005; Tabler and Tsagris 2004). For an enlightening account of the viroid discovery, readers are referred to Diener (2003). In the present article, we focus on the viroid RNA structural elements and cellular proteins that are crucial for replication, intracellular and intercellular trafficking, and symptom expression. We discuss the current status of knowledge and raise important issues for future investigations. We stress the need to develop new experimental tools and resources to advance our understanding of the mechanisms of viroid infection and diseases. Finally, we discuss how research on viroidhost interactions has contributed, and can continue to contribute, insights into fundamental biological problems.

General features of viroids and viroid infection.

Approximately 30 species of viroids and many of their variants currently are known. A recent compilation of viroid species 
and their classifications (Flores et al. 2005) and the Subviral RNA Database (Rocheleau and Pechat 2006) present an updated taxonomy as well as sequence and structural analyses.

Viroids are classified into two families: Pospiviroidae and Avsunviroidae. The salient features that distinguish the two families are listed in Table 1. The type member of the former is PSTVd and that of the latter is Avocado sunblotch viroid (ASBVd). All viroids are single-stranded, circular RNAs. Without considering sequence duplications, viroid RNAs range in size from 250 to $400 \mathrm{nt}$. The members of Avsunviroidae have limited sequence conservation and most of them have highly branched secondary structures (Fig. 1). They all have ribozyme activities and replicate in the chloroplasts. Their hosts are mostly woody species.

The members of Pospiviroidae have highly conserved regions in their rod-shaped secondary structure, replicate in the nucleus, and generally are considered to lack ribozyme activity. Five broad structural domains are defined in the secondary structure of viroids in Pospiviroidae. These include the left-terminal domain, pathogenicity domain, central domain that contains a central conserved region (CCR), variable domain, and rightterminal domain (Keese and Symons 1985) (Fig. 1). Their hosts are mostly herbaceous species.

The establishment of systemic infection by both families of viroids involves the following mechanistic steps: i) import into specific subcellular organelles (the nucleus for Pospiviroidae and chloroplast for Avsunviroidae), ii) replication, iii) export out of the organelles, iv) cell-to-cell trafficking, v) entry into the vascular tissue, vi) long-distance trafficking within the vascular tissue, and vii) exit from the vascular tissue and subsequent invasion of nonvascular cells to repeat the cycle (Fig. 2) (Ding et al. 2005; Flores et al. 2005; Tabler and Tsagris 2004). Accomplishment of each step likely involves direct interactions between specific viroid motifs and cellular factors. It is crucial that viroid RNAs are protected against cellular degradation at each step.

\section{RNA motifs and cellular factors for viroid replication.}

Molecular models describing how viroid RNAs are transcribed and processed into mature forms were proposed 20 years ago, and the basic features have stood the test of numerous studies. Here, we first briefly describe the mechanical features of these models and then discuss the RNA motifs and cellular factors involved in the replication.

Rolling circle replication. The members of Pospiviroidae replicate via an asymmetric rolling circle mechanism (Branch and Robertson 1984) (Fig. 3A). The incoming (+)-circular RNA initially is transcribed into concatemeric linear (-)-strand RNA, which then serves as the replication intermediate for the synthesis of concatemeric, linear (+)-strand RNA. This (+)strand RNA subsequently is cleaved into unit-length monomers that are ligated into circles.

In contrast, the members of Avsunviroidae adopt a symmetric rolling circle replication mechanism (Branch and Robertson 1984; Daròs et al. 1994; Navarro et al. 1999) (Fig. 3B). The circular (+)-RNA is transcribed into linear, concatemeric (-)strand RNA. Instead of serving as the direct template for the synthesis of linear concatemeric (+)-strand RNA, the concatemeric (-)-strand RNA is cleaved into unit-length molecules followed by circularization. The circular (-)-RNA then serves as the template for the synthesis of linear, concatemeric (+)strand RNA, which subsequently is cleaved into unit-length monomers and circularized. Thus, this mechanism involves two rolling circles.

Subcellular sites for replication. Members of Pospiviroidae replicate in the nucleus. Subcellular fractionation (Schumacher et al. 1983; Spiesmacher et al. 1983; Takahashi and Diener 1975) and in situ hybridization (Harders et al. 1989; Qi and Ding 2003a) localized PSTVd in the nucleus. Other members of the Pospiviroidae, including Coconut cadang cadang viroid (CCCVd) and Citrus exocortis viroid (CEVd), also have been localized in the nucleus by in situ hybridization (CCCVd: Bonfiglioli et al. 1994, 1996; CEVd: Bonfiglioli et al. 1996), as well as by subcellular fractionation (CEVd: Grill and Semancik 1979; Semancik et al. 1976).

Within the nucleus, viroid RNAs exhibit distinct subnuclear localization patterns. An early in situ hybridization study localized both the (+) and (-) strands of PSTVd in the nucleoli of nuclei isolated from infected tomato (Harders et al. 1989). In tissue sections of infected plants, in situ hybridization revealed that CEVd was localized throughout the nucleus, whereas CCCVd was distributed mostly in the nucleolus and, to a lesser extent, in the nucleoplasm (Bonfiglioli et al. 1996). Both the (+) and (-)RNAs of these viroids exhibited similar distribution patterns, although the hybridization signal for the (-)-RNA was much weaker (Bonfiglioli et al. 1996).

Qi and Ding (2003a) showed that, in chemically fixed infected protoplasts of Nicotiana benthamiana and on cryosections of infected tomato and $N$. benthamiana leaves, the $(-)$-PSTVd RNA is localized in the nucleoplasm, whereas the (+)-PSTVd RNA is localized in both the nucleolus and the nucleoplasm with various spatial patterns. These observations support a model in which PSTVd transcription takes place in the nucleoplasm and, whereas the (-)-strand RNA templates are anchored in the nucleoplasm by the transcription machinery, the concatemeric linear (+)-RNAs traffic into the nucleolus for cleavage and ligation (Fig. 3A). Current data, however, do not rule out the possibility that cleavage and ligation also occur in the nucleoplasm and the circular products traffic into the nucleolus. Identification and subcellular localization of the cellular factors involved in cleavage and ligation should help clarify the issue.

In Avsunviroidae, both the (+) and (-) strands of ASBVd (Bonfigolioli et al. 1994; Lima et al. 1994; Navarro et al. 1999) and Peach latent mosaic viroid (PLMVd) (Bussière et al. 1999) are localized to the chloroplasts of infected cells, providing compelling evidence that these viroids replicate in the chloroplasts. PLMVd is more concentrated in palisade parenchyma cells than in other cells of an infected leaf (Bussière et al. 1999). The biological significance of this tissue-tropism remains to be understood. It could imply the existence of tissuespecific host factors that function to enhance or restrict replication. An outstanding question is whether all plastids, or only chloroplasts, could support viroid replication. Another ques-

Table 1. Comparison of distinguishing features of the families Pospiviroidae and Avsunviroidae

\begin{tabular}{lll}
\hline & & Family \\
\cline { 2 - 3 } Features & \multicolumn{1}{c}{ Pospiviroidae } & Avsunviroidae \\
\hline Secondary structure & Rod-shaped & Branched for most members \\
Replicate site & Nucleus & Chloroplast \\
Rolling circle & Asymmetric & Symmetric \\
Ribozyme activity & Uncertain & Yes for all current members \\
Hosts & Mostly herbaceous species & Mostly woody species \\
\hline
\end{tabular}


tion is why the chloroplast and nucleus, but not the mitochondrion, are the organelles of choice for the replication of viroid RNAs. Resolving these issues is of great interest to broaden our knowledge of the molecular processes in these organelles and to further our understanding of the molecular basis for the evolution of infectious RNAs.

The enzyme machinery for transcription. The DNA-dependent RNA polymerase II (Pol II) is generally accepted to be involved in the transcription of members of Pospiviroidae. Three lines of observations support this hypothesis. First, purified tomato Pol II complex can transcribe the (+)-PSTVd RNA template in vitro (Rackwitz et al. 1981). Second, $\alpha$-amanitin inhibits the replication of PSTVd (Mühlbach and Sänger 1979; Schindler and Mühlbach 1992), Cucumber pale fruit viroid (Mühlbach and Sanger 1979), Hop stunt viroid (HSVd) (Yoshikawa and Takahashi 1986), and CEVd (Flores 1989; Flores and Semancik 1982; Rivera-Bustamante and Semancik 1989; Semancik and Harper 1984). Low concentrations of $\alpha$ -

(+) ASBVd

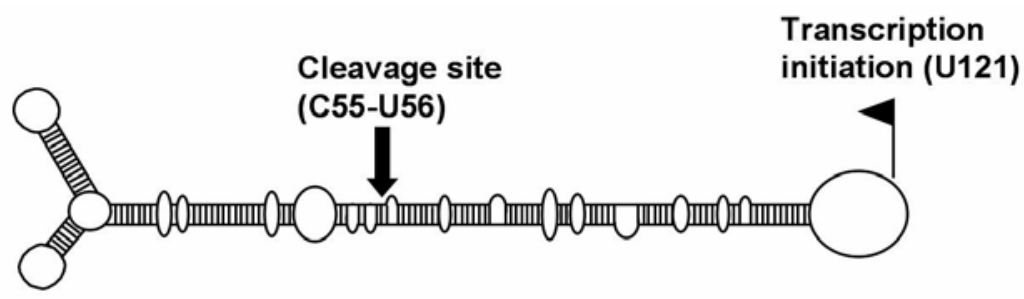

(-) ASBVd

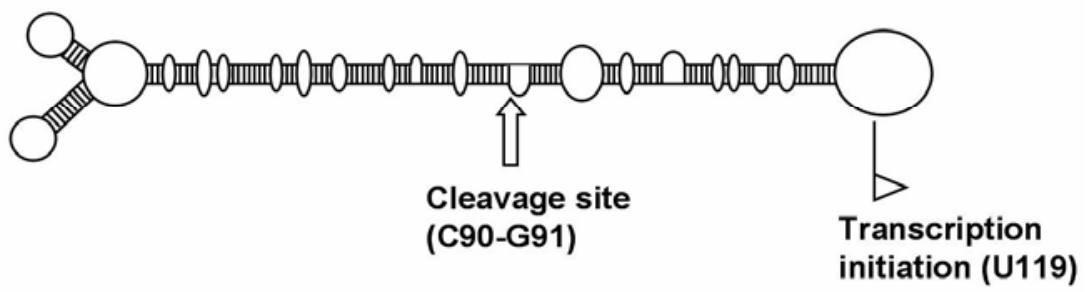

(+) PLMVd
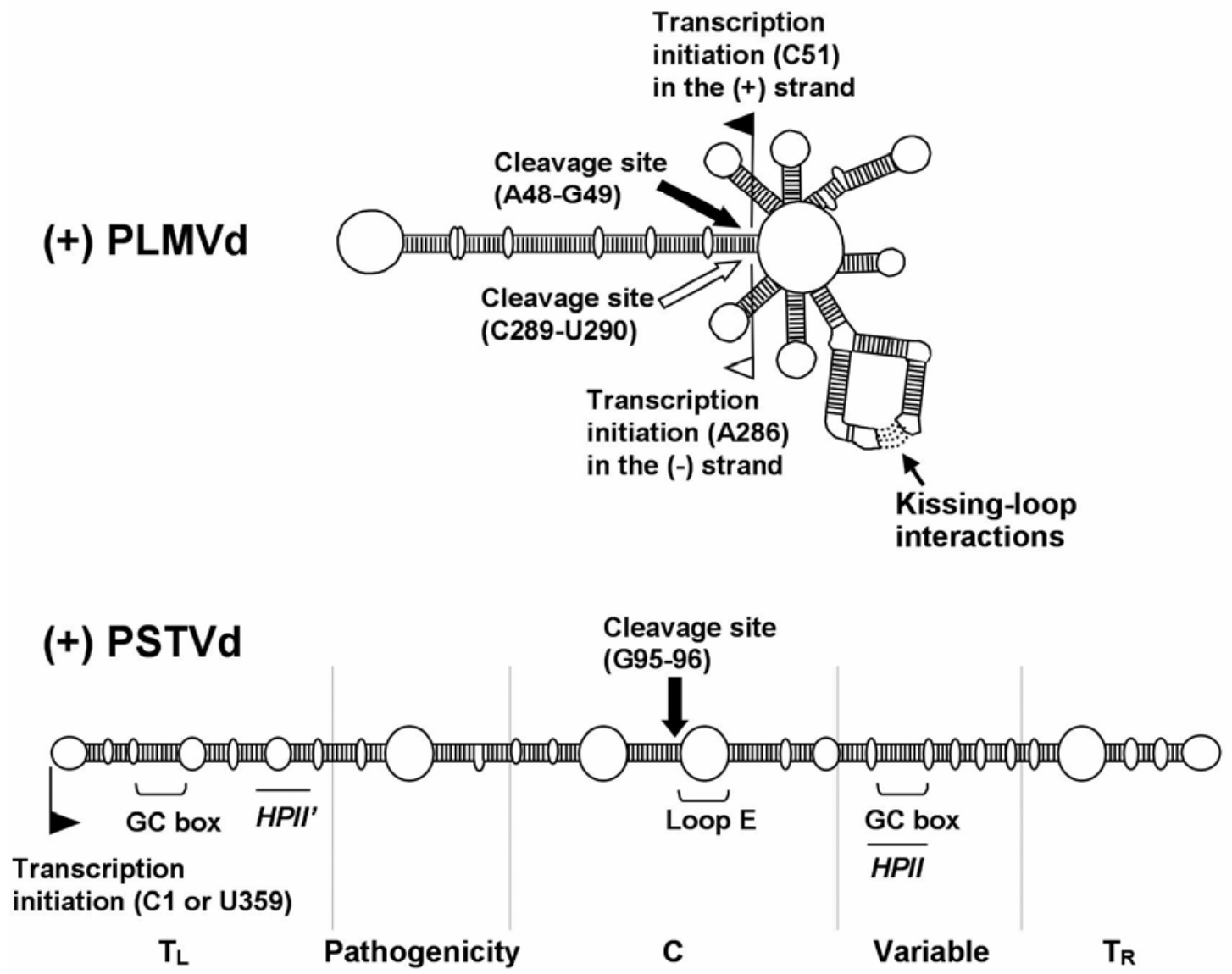

Fig. 1. Secondary structures of representative viroids from the two viroid families, Avsunviroidae: Avocado sunblotch viroid (ASBVd) and Peach latent mosaic viroid (PLMVd), and Pospiviroidae: Potato spindle tuber viroid (PSTVd). The transcription initiation sites on the viroid genomic RNAs are indicated. Note that for ASBVd and PSTVd, these sites are mapped to terminal loops. The transcription initiation site for the (-)-PSTVd RNA template remains to be determined. For PLMVd, the dashed lines indicate kissing-loop interactions. For PSTVd, the five structural domains (Keese et al. 1985) are indicated. $T_{L}=$ left-terminal domain, $\mathrm{C}=$ central domain, and $\mathrm{T}_{\mathrm{R}}=$ right-terminal domain. HPII' and HPII indicate nucleotide sequences that base pair to form the metastable hairpin II structure. 
amanitin that are known to specifically inhibit Pol II activity also inhibit transcription of the (+)-PSTVd template into (-)RNAs in assays in which the template was added externally to the nuclear extracts prepared from healthy potato plants (Fels et al. 2001; Kolonko et al. 2006). Third, co-immunoprecipitation showed that both the $(-)$ and $(+)$ strands of CEVd are associated in vivo with the largest subunit of Pol II in tomato (Warrilow and Symons 1999).

Based on the $\alpha$-amanitin inhibition results, Schindler and Mühlbach (1992) proposed that Pol II is directly involved in the transcription of both the (-)-linear concatemeric and (+)circular PSTVd templates. Given the presence of cellular RNA-directed RNA polymerases (RDRs) in plants (Wassenegger and Krczal 2006), one may ask whether an RDR also plays a role in PSTVd replication. For instance, is it possible that Pol II transcribes the circular (+)-template whereas an RDR transcribes the linear concatemeric (-)-template? The role of RDR in synthesizing double-stranded RNAs as Dicer substrates during RNA silencing (Baulcombe 2004; Wassenegger and Krczal 2006) has been established. Therefore, the involvement of a cellular RDR in viroid replication warrants an investigation.

For the transcription of viroids in Avsunviroidae, two types of DNA-dependent RNA polymerases in the chloroplast need to be considered: the nuclear-encoded and phage-like single-unit polymerase (NEP) and the plastid-encoded bacterial-like multi-unit RNA polymerase (PEP) (Stern et al. 1997). In vitro transcription assays with chloroplasts isolated from infected avocado leaves suggested that the NEP is involved in ASBVd transcription, based on its resistance to tagetitoxin at concentrations that effectively inhibit the transcription of chloroplast genes normally transcribed by PEP (Navarro et al. 2000). The possibility that another tagetitoxin-resistant machinery is involved in ASBVd replication cannot yet be ruled out (Navarro et al. 2000). With unsuccessful attempts to establish a transcription system for PLMVd in cell extracts of several plant species, Pelchat and associates (2002) tested whether the Escherichia coli DNAdependent RNA polymerase would transcribe PLMVd in vitro. The observed transcription led to the suggestion that, in infected plant cells, the PEP catalyzes transcription of PLMVd. However, recent work suggests that NEP more likely is involved in the transcription of PLMVd in vivo (Delgado et al. 2005). Thus, further biochemical and genetic studies will be necessary to verify the involvement of the proposed enzyme machinery in the transcription of the Avsunviroidae members. In this regard, an in vitro system based on purified chloroplasts that can be primed to support replication would be valuable.

It should be pointed out that DNA-dependent RNA polymerases not only transcribe viroid RNA templates, but also the human hepatitis delta virus RNA (Lai 2005; Taylor 2003). These represent remarkable examples of how pathogens have evolved the capacity to utilize the cellular transcription machinery for their replication and raise some basic questions of broad interests for future investigations. What cellular factors are recruited to transcribe an RNA template by a DNA-dependent RNA polymerase? How does the cellular transcription machinery switch between DNA and RNA templates? Do these factors recognize only RNA templates or do they have the dual capacity to recognize DNA and RNA templates for transcription? Are these simply special cases in which infectious RNAs have evolved structural features to hoax the cellular machinery for their selfish purpose, or are they only the tip of the iceberg of a cellular system that replicates endogenous RNAs? Investigating these questions may provide new insights into the functions of the cellular transcription machinery and also, perhaps, the evolution of these unique pathogens.

RNA motifs for transcription initiation. Transcription initiation sites have been mapped for two members of Avsunviroidae, using viroid RNAs isolated from infected plants. For ASBVd, in vitro capping and RNase protection assays mapped the initiation site on the (+)-RNA to U121 and that on the (-)RNA to U119, respectively, both located in the A+U-rich terminal loops of the predicted RNA secondary structures (Fig. 1) (Navarro and Flores 2000). The initiation site of PLMVd for in vitro transcription directed by E. coli polymerase is mapped to U332 (Pelchat et al. 2002). RNA-protein footprinting experiments showed that this left loop is the binding site for the $\beta$ and $\beta^{\prime}$ subunits of the $E$. coli enzyme (Pelchat and Perreault 2004). The in vivo significance of these sites remains to be seen, in light of recent work that mapped the in vivo initiation sites of PLMVd to C51 in the (+)-strand RNA and A286 in the (-)-strand RNA, in similar 6- to 7-bp double-stranded motifs (Fig. 1) (Delgado et al. 2005).

Mapping the transcription initiation sites for members of Pospiviroidae has been achieved only recently for PSTVd using

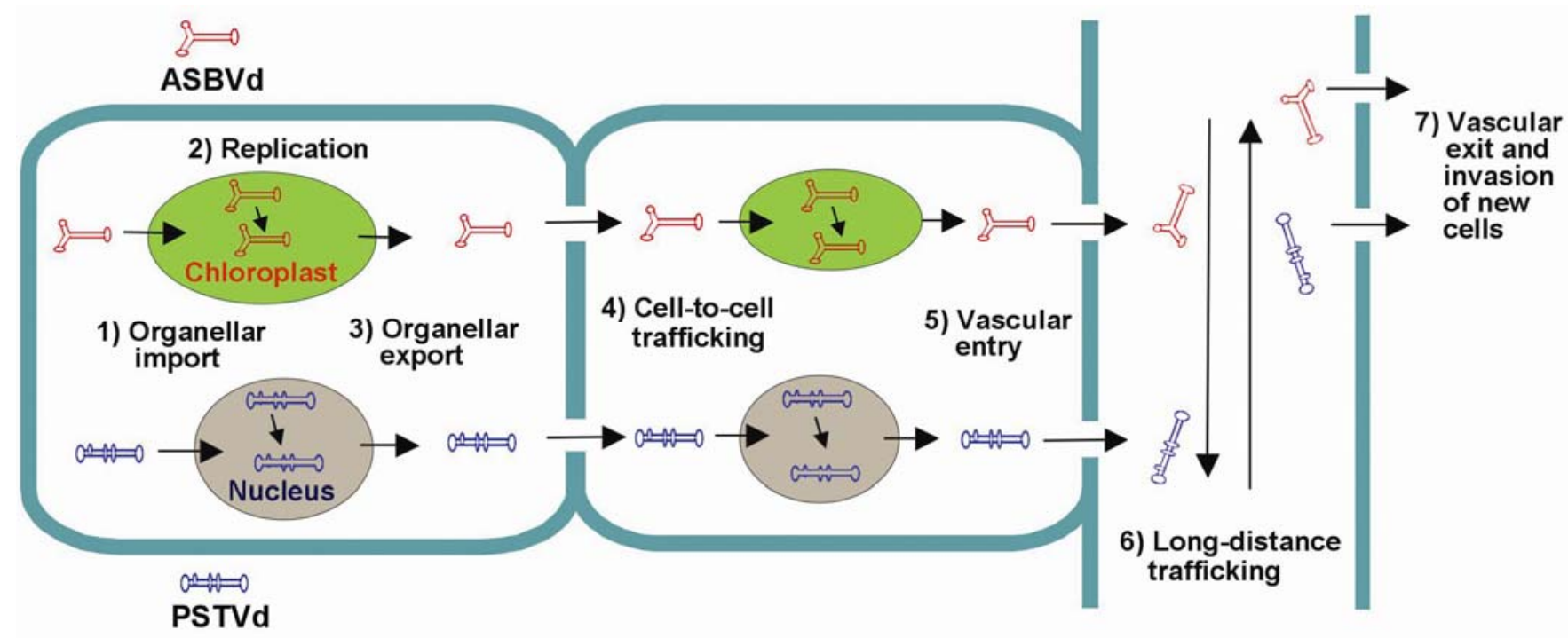

Fig. 2. Distinct steps of systemic infection of Avocado sunblotch viroid (ASBVd) and Potato spindle tuber viroid (PSTVd), type members of the two viroid families. The mechanisms of the different trafficking steps for the family Avsunviroidae remain to be investigated. (Modified from Ding et al. 2005, with permission from Elsevier Ltd.) 
an in vitro transcription system. With a combination of protocols to remove cellular RNAs and, thereby, enrich the de novo synthesized (-)-strand PSTVd RNAs from the circular (+)RNA templates in potato nuclear extracts and primer extension, Kolonko and associates (2006) mapped the transcription initiate site on the circular (+)-RNA to U359/C1 of the left terminal loop (Fig. 1). Because of the low resolution of sequencing gels, it is not possible to determine precisely whether U359 or C1 is the exact initiation site. Site-directed mutagenesis in combination with infection studies in tomato revealed that the $\mathrm{C} 1 \mathrm{G}$ mutation was maintained stably, whereas U359G reverted to wild type, suggesting that perhaps U359 is the bona fide initiation site. It is notable that these data are consistent with previous in vitro studies showing that Pol II binds to the terminal loop or loops of PSTVd (Goodman et al. 1984). These observations establish a basis for further investigations to determine whether the in vitro transcription initiation site is the same as that used in vivo. The transcription initiation sites on the (-)-strand template also remain to be determined.

A critical issue for all viroids is that bona fide promoter sequences have not been characterized fully. This obviously is one of the most pressing issues that need to be addressed in order to fully understand how viroid RNA templates are recognized and transcribed by the cellular machinery.

RNA motifs and protein factors for cleavage and ligation. The sequence and structural conservation of the CCR of several members of Pospiviroidae suggests its potential importance in viroid processing during replication (Candresse et al. 1990; Diener 1986; Hashimoto and Machida 1985; Meshi et al. 1985; Tabler and Sänger 1985; Visvader et al. 1985). Extensive in vitro studies provided evidence to support this hypothesis (Baumstark and Riesner 1995). Furthermore, in vitro studies with longer than unit-length PSTVd transcripts mapped the cleavage and ligation site to between G95 and G96 (Baumstark et al. 1997). The first cleavage at the $5^{\prime}$ end of G96 occurs in a metastable tetraloop motif, which results in a conformational change to form a stable loop $\mathrm{E}$ that drives the second cleavage at the $3^{\prime}$ end of G95 and subsequent ligation (Baumstark et al. 1997). Recent work with a minicircle RNA showed that the CCR contains all the necessary elements for cleavage and ligation (Schrader et al. 2003). It is important to note that processing also can occur outside CCR, with the specific sites to be elucidated (Hammond et al. 1989; Tabler et al. 1992). A key question that remains to be answered is whether single or multiple sites are used for processing in vivo.

Weak self-cleavage of PSTVd RNAs has been reported by some researchers (Robertson et al. 1985) but not by others (Tabler and Sänger 1985; Tsagris et al. 1987a,b). It generally is thought that a cellular RNase which remains to be identified catalyzes the cleavage of concatemeric RNAs (Tsagris et al. 1987a,b). Reasoning that the general difficulty of demonstrating self-cleavage of RNAs in Pospiviroidae could be attributed to the interference of nonribozyme RNA sequences in the substrates used during in vitro assays, Liu and Symons (1998)
PSTVd

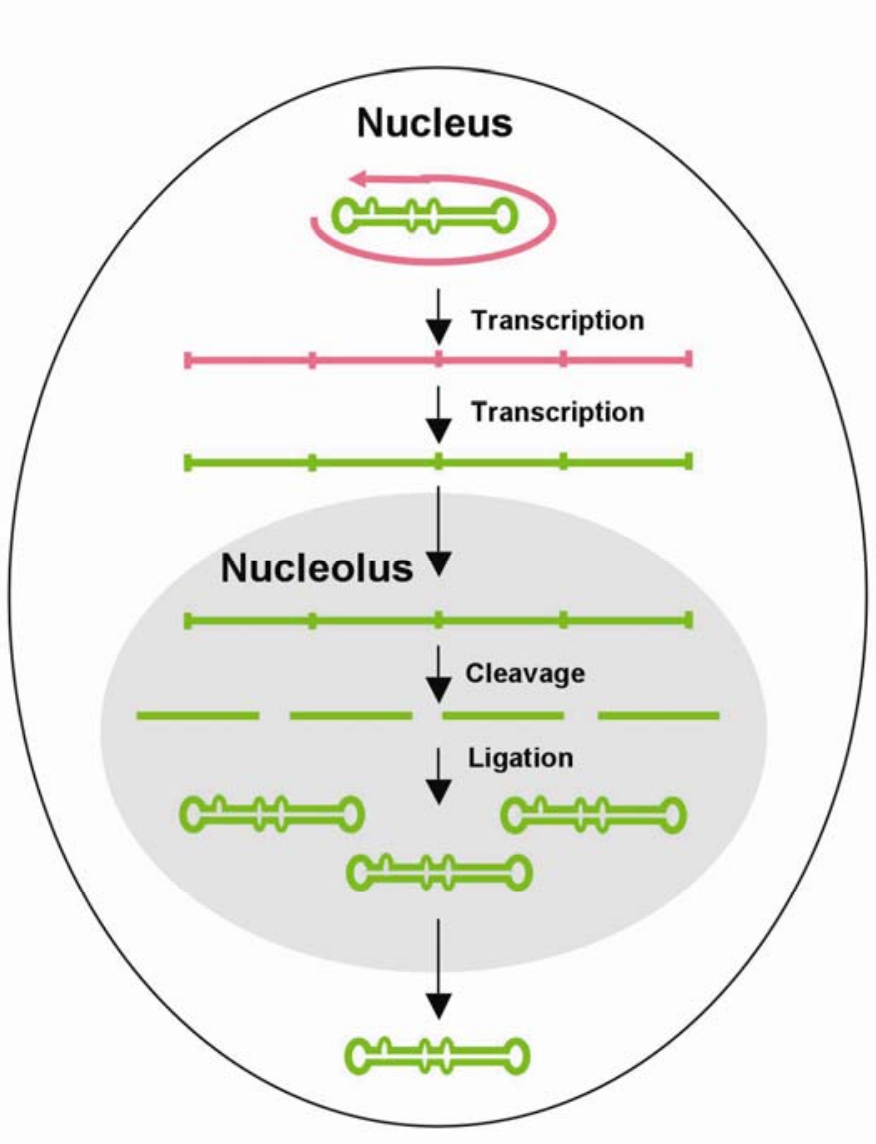

ASBVd

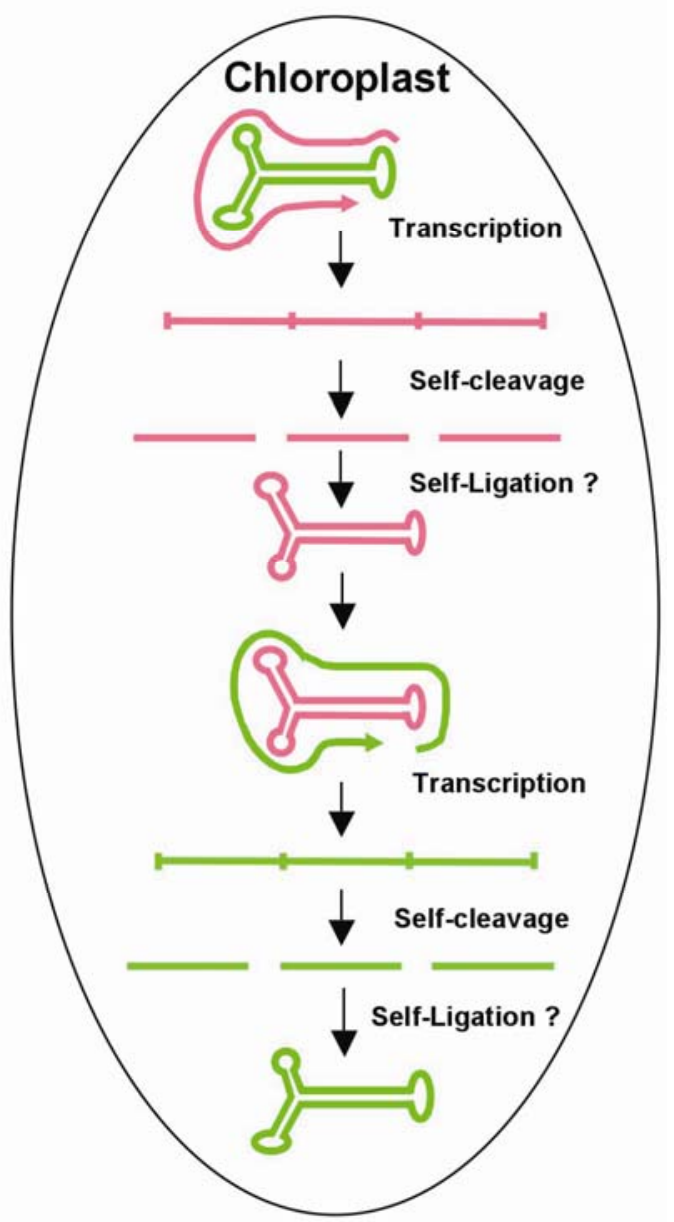

Fig. 3. Asymmetric rolling circle replication of Potato spindle tuber viroid (PSTVd) and symmetric rolling circle replication of Avocado sunblotch viroid (ASBVd). The secondary structures of the genomic or circular RNAs are sketched to facilitate illustration of the approximate transcription initiation sites. 
tested self-cleavage of an RNA substrate derived from the CCR of CCCVd. They showed that self-cleavage occurred after the RNA substrate was denatured with methylmercuric hydroxide and then incubated with spermidine. Further analyses mapped the cleavage site in the lower part of a loop in the CCR. Structural analyses have shown that sequences in the right terminal domain of HSVd may form a hammerhead-like ribozyme, structurally similar to that of the Avsunviroidae (discussed below) (Amari et al. 2001). Therefore, it remains an open question as to whether all or some members of Pospiviroidae do posses self-cleavage activities that are important for replication. The cellular factors to facilitate or directly catalyze the cleavage remain unknown. Identification of any such factors could contribute useful knowledge about the general mechanisms of RNA processing in plants.

Ligation of PSTVd RNAs occurs with low efficiency autocatalytically but with high efficiency enzymatically (Baumstark et al. 1997). It has long been known that wheat germ extract (WGE) and Chlamydomonas spp. contain ligase activities that circularize PSTVd linear RNAs (Branch et al. 1982; Kikuchi et al. 1982); however, the biochemical identity of any enzymes remains unknown. Achieving circularization likely was one of the major milestones during the evolution of viroid RNAs, which led to the formation of RNA molecules with structural stability and flexibility that are critical for survival and replication or movement. Therefore, identifying this ligase has unique significance for understanding the infection and evolution of viroid RNAs. In a recent study, characterization of the WGE tRNA ligase activities led to the cloning of the corresponding gene from Arabidopsis (Englert and Beier 2005). Our preliminary work suggests that this ligase may not be involved in PSTVd ligation (X. Zhong, A. Itaya, R. Takeda, and B. Ding, unpublished data). Further work will be needed to fully characterize the ligase or ligases for the circularization of the PSTVd RNAs.

The viroids in Avsunviroidae form hammerhead ribozymes in both the (+) and (-) strands of RNAs to catalyze self-cleavage in vitro (Beaudry et al. 1995; Fadda et al. 2003; Forster et al. 1988; Hernandez and Flores 1992; Hutchins et al. 1986; Navarro and Flores 1997). Analyses of Chrysanthemum chlorotic mosaic viroid (CChMVd) showed that RNA sequences peripheral to the ribozyme structure can greatly enhance selfcleavage activities (De la Peña et al. 2003; Khvorova et al. 2003), a finding that has broadened our understanding of ribozyme structure and functions. The discovery of hammerhead ribozymes in viroids (Hutchins et al. 1986) and satellite RNAs of plant viruses (Forster and Symons 1987; Prody et al. 1986) established a paradigm for subsequent discoveries of this class of ribozymes in cellular RNAs of animals (Epstein and Gall 1987; Ferbeyre et al. 1998; Rojas et al. 2000; Zhang and Epstein 1996) and plants (Przybilski et al. 2005).

Nonenzymatic intra- and intermolecular ligation has been demonstrated for PLMVd RNA in vitro (Lafontaine et al. 1995). The self-ligation produces a 2',5'-phosphodiester bond in vitro that may protect the circular RNA from cleavage by cellular enzymes (Côté and Perreault 1997). Significantly, Côté and associates (2001) demonstrated the presence of the 2',5'-phosphodiester bond at the ligation site of the circular PLMVd RNAs isolated from infected peach plants. Thus, this evolutionarily primitive phosphodiester linkage still occurs in nature, making PLMVd an excellent model to further investigate the evolution and modern significance of this linkage.

Although evidence is compelling that cis-acting ribozyme structures drive cleavage of the replication intermediates of Avsunviroidae members, specific cellular factors may promote or enhance these processes. Using UV-crosslinking and biochemical approaches, Daròs and Flores (2002) identified a chloroplast protein, PARBP33, that interacts with ASBVd in vivo. This protein has an RNA-binding motif and its presence accelerates self-cleavage of concatemeric ASBVd RNAs in vitro (Daròs and Flores 2002). The in vivo role of this factor for viroid replication and general RNA processing remains to be fully understood.

Other RNA motifs potentially important for replication. In addition to specific sites for transcription initiation and processing, other structural elements of viroid RNAs may play various roles to assist or modulate these functions. Many mutations scattered throughout the PSTVd genome each inhibit infection in mechanically inoculated plants, which often have been interpreted as inhibition of replication (Hammond and Owens 1987; Hu et al. 1996; Owens et al. 1986, 1991).

Fels and associates (2001) noted two GC boxes in the PSTVd secondary structure (Fig. 1). Mutational studies suggest that they may play a role in transcription (Kolonko et al. 2006). The left terminal domain and one of the GC boxes are proposed to constitute the transcription domain of PSTVd (Kolonko et al. 2006). This model should help design further experiments to investigate the role of this domain in transcription.

A metastable hairpin II (HPII) structure is predicted to form through base interactions involving nucleotide sequences 227 to 237 and 318 to 328 (Fig. 1, HPII and HPII', respectively) during thermal denaturation of the PSTVd secondary structure (Henco et al. 1979; Riesner et al. 1979). Mutations that are predicted to inhibit the formation of HPII always revert to wild type in mechanically inoculated plants, leading to the postulation that HPII plays an essential role in the transcription of the (-)-strand template, perhaps as a binding site for a cellular factor (Candresse et al. 2001; Kolonko et al. 2006; Loss et al. 1991; Owens et al. 1991; Qu et al. 1993). The HPII structure has been detected in vitro and in vivo (Schröder and Riesner 2002), supporting the importance of this structure in viroid replication.

The loop E located in the CCR of PSTVd (Figs. 1 and 4) also is implicated in replication. A single nucleotide substitution, $\mathrm{C} 259 \mathrm{U}$, in loop E enhances replication by 5- to 10-fold in cultured cells of tobacco BY2, but not in those of $N$. benthamiana (Qi and Ding 2002). The enhanced replication in tobacco cells may be responsible for the adaptation of PSTVd to this host (Wassenegger et al. 1996; Zhu et al. 2002). The U257A substitution in loop E also enables PSTVd to infect tobacco (Qi and Ding 2002; Zhu et al. 2002). It was suggested that these mutations enhance transcription (Qi and Ding 2002). In a recent study, Zhong and associates (2006) used comparative sequence analysis with isotericity matrices (IM) (Leontis et al. 2002) to infer specific non-Watson-Crick base pairing in PSTVd loop E (Fig. 4). The inferred tertiary structural model of PSTVd loop E extends and refines previous findings based on UV crosslinking (Branch et al. 1985) and chemical mapping (Gast et al. 1996). The IM analysis showed that the model accounts for the reported natural sequence variations and viable mutants in PSTVd and other viroids in Pospiviroidae. Furthermore, this model allowed engineering of mutations that would disrupt the loop E tertiary structure as well as compensatory mutations that restore the structure. In vitro and in vivo experiments showed that the loop E-disruptive mutants (A99C and A261C) are defective in replication in $N$. benthamiana protoplasts, providing loss-of-function genetic evidence for a critical role of loop $\mathrm{E}$ in replication. The data also provide strong evidence that loop E exists in vivo. Further analyses suggest that loop E is critical for transcription, although the specific mechanisms remain to be determined (Zhong et al. 2006).

A kissing-loop interaction was predicted to occur in PLMVd and CChMVd based on chemical mapping and co-variation analysis (Bussière et al. 2000) (Fig. 1). A recent extensive 
study using site-directed mutagenesis and co-variation analyses provided solid evidence that the interaction is critical for CChMVd infectivity in inoculated chrysanthemum plants (Gago et al. 2005). The specific mechanisms remain to be understood; however, current evidence suggests that the kissing-loop interaction is at least critical to maintain the stability of the viroid RNA (Bussière et al. 2000; Gago et al. 2005).

It is important to bear in mind that, although mutational analyses in conjunction with whole-plant infection assays have identified viroid motifs important for infection at the wholeplant level, interpretation of how a mutation affects a specific step of the infection process requires several critical considerations. First, reversion of a mutated nucleotide to wild type or a gain-of-function mutation provides strong evidence for the role of the affected RNA structure in a specific process. To be conclusive, however, loss-of-function genetic evidence is necessary. Second, the whole-plant infection assay does not reveal whether a mutation impairs replication or intracellular or systemic trafficking to cause failure in systemic infection. Therefore, further progress in identifying the viroid motifs that mediate a specific step of the infection process will require the application of multiple approaches. In particular, the tertiary structures of the various RNA motifs as well as their existence in vivo will need to be determined in order to facilitate further mechanistic studies.

\section{Intracellular trafficking of viroid RNAs.}

In order for replication to take place, viroid RNAs must be localized to the correct subcellular sites to gain access to the cellular machineries that recognize, transcribe, and process the RNAs. In contrast to the mechanisms involved in replication, the mechanisms responsible for intracellular localization have received much less attention in previous studies. This should be one of the major areas for future investigations. Elucidating the mechanisms of intracellular localization of viroids will be necessary not only to fully understand the infection of these RNAs, but also should yield insights into the poorly understood mechanisms of intracellular localization of RNAs in a plant cell.

Nuclear transport of PSTVd. In permeabilized protoplasts, nuclear import of fluorescently labeled PSTVd in vitro transcripts can be inhibited specifically by nonlabeled transcripts of PSTVd, suggesting that PSTVd import is a specific and regulated process (Woo et al. 1999). Using an independent approach, Zhao and associates (2001) showed that PSTVd can function in cis to mediate nuclear import of a large fusion RNA in $N$. benthamiana leaves. These observations suggest that PSTVd has a nuclear import signal which remains to be identified. The cellular machinery that recognizes and imports the viroid RNA is not known. How the viroid RNAs exit the nucleus also remains to be investigated.

Chloroplast transport of Avsunviroidae. How members of the Avsunviroidae enter the chloroplast to initiate replication is poorly understood. One possibility is that these RNAs elicit abnormal changes in the permeability of the chloroplast envelope so that they enter the organelle via a unique mechanism. Alternatively, these RNAs have evolved a motif that is recognized by a machinery for normal RNA import into the chloroplast that is yet to be discovered. Elucidating how viroid RNAs enter and exit the chloroplasts can enhance our understanding of the basic biology of chloroplasts, besides gaining crucial insights into some critical steps of the viroid infection cycle.

\section{Viroid RNA motifs and cellular factors}

\section{for intercellular trafficking.}

To establish a systemic infection, viroid RNAs must traffic from initially infected cells into neighboring cells and distant organs. Cell-to-cell trafficking of PSTVd occurs through plas- modesmata (Ding et al. 1997) and long-distance trafficking occurs through the phloem (Palukaitis 1987; Zhu et al. 2001). In contrast to viruses which encode one or more proteins to facilitate their cell-to-cell and long-distance trafficking (Lucas 2006; Scholthof 2005), viroids must rely on direct interactions with cellular factors to traffic within a plant. Because trafficking of RNAs also plays critical roles in systemic regulation of gene expression and control of plant development, investigating viroid trafficking may help understand the general mechanisms (Ding et al. 2005).

RNA motif-mediated trafficking. The first hint for regulated trafficking of viroid RNAs came from the demonstration that two mutations in the right-terminal domain of PSTVd do not affect replication when inoculated by agroinfiltration in tomato roots, but appear to affect systemic infection (Hammond 1994). Whether the mutations affected replication of the viroid in different cell types has not been determined. Therefore, it remains an open question as to whether these mutations truly inhibit trafficking. Further studies provided evidence for regulated trafficking. Using microinjection, Ding and associates (1997) showed that PSTVd could function in cis to potentiate cell-to-cell trafficking of a heterologous RNA, suggesting that the viroid RNA has a motif that mediates trafficking. Zhu and associates $(2001,2002)$ demonstrated that PSTVd traffics into sepals but not the other floral organs in developing and mature flowers, suggesting that the phloem has a mechanism to recognize and traffic PSTVd RNAs into selective sink organs. Furthermore, they showed that phloem entry and exit appear to be
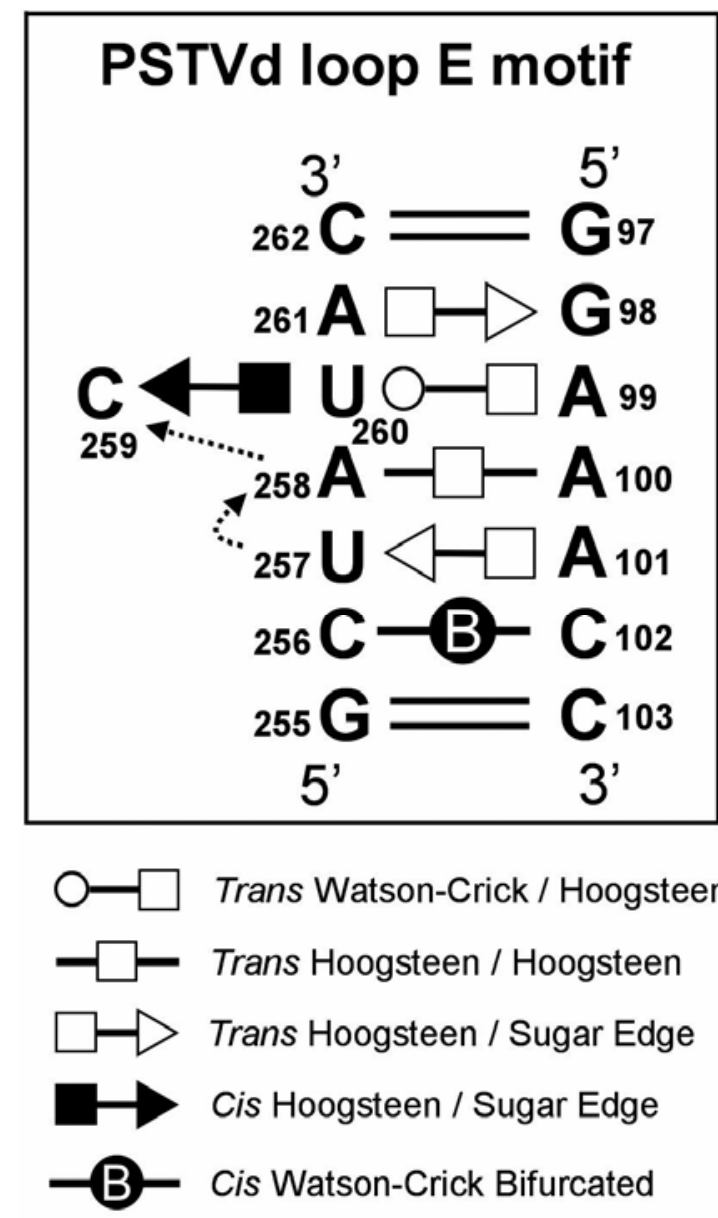

Fig. 4. Tertiary structure of Potato spindle tuber viroid (PSTVd) loop E, inferred by comparative sequence analysis with isostericity matrices. (From Zhong et al. 2006, with permission from American Society for Microbiology.) 
differently regulated, because some PSTVd variants could enter and traffic in the phloem but do not exit the phloem (Zhu et al. 2002)

Recent mutational studies on two PSTVd strains, PSTVd ${ }^{\mathrm{NT}}$ and PSTVd ${ }^{\mathrm{NB}}$, which differ by five nucleotides, identified a bipartite RNA motif that is required for trafficking from bundle sheath to mesophyll, but not required for trafficking in the reverse direction (Qi et al. 2004). Importantly, this requirement applies to trafficking only in young leaves, not in mature leaves (Qi et al. 2004). Thus, plant development also is a major factor for the fine-tuning of trafficking controls. Whether the bipartite motif interacts with separate cellular factors or they form a particular tertiary structural motif via conformational changes to interact with a cellular factor for trafficking remains an outstanding question. Systemic trafficking of plant RNAs also appears to be directed by RNA motifs and regulated by plant development (Haywood et al. 2005).

Cellular factors involved in viroid RNA trafficking. Several promising candidate cellular factors that facilitate trafficking of viroid RNAs have been reported. In vitro binding assays showed that the phloem lectin PP2 from cucumber (CsPP2) binds HSVd (Gómez and Pallás 2001; Owens et al. 2001). This interaction also occurs in vivo, as shown by co-immunoprecipitation (Gómez and Pallás 2004). CsPP2 has an RNA-binding motif (Gómez and Pallás, 2004). Both CsPP2 (Golecki et al. 1999; Gómez and Pallás 2004) and HSVd (Gómez and Pallás 2004) can traffic from rootstocks into scions in heterografts, suggesting that CsPP2 contributes to long-distance trafficking of HSVd RNAs (Gómez and Pallás 2001, 2004; Owens et al. 2001). In a more recent study, Gómez and associates (2005) identified two proteins that bind ASBVd. These include the previously characterized CmmLec17 (Dinant et al. 2003) and a 14-kDa protein which remains to be characterized. CmmLec17 can move long distances from rootstocks to scions in heterografts, suggesting a possible role of this protein in RNA trafficking. More direct evidence for the role of any of these phloem proteins in viroid trafficking will come from genetic and molecular studies.

A tomato protein, VIRP1, that interacts with PSTVd was isolated in an expression library screening (Martinez de Alba et al. 2003). VIRP1 interacts in vitro with the right-terminal regions of PSTVd and HSVd, albeit more weakly in the latter case (Gozmanova et al. 2003; Maniataki et al. 2003). Two asymmetric internal loop motifs are specifically involved in the interaction (Gozmanova et al. 2003). Specific mutations in these motifs result in loss of VIRP1 binding and loss of infectivity, suggesting that VIRP1-loop interaction is important for infection (Gozmanova et al. 2003). Other mutations in the right-terminal domain of PSTVd abolish infection of tomato by mechanical inoculation, presumably as a result of inhibited movement (Hammond 1994; discussed above). These mutations also compromise interactions with VIRP1, raising the possibility that VIRP1 interacts with the right-terminal domain of PSTVd to facilitate trafficking (Maniataki et al. 2003). This can be tested further by a combination of molecular, genetic, and cellular experiments.

Given that distinct RNA motifs may mediate directional trafficking between different cells, it is conceivable that at least some protein factors function in a cell-specific manner to potentiate RNA trafficking (Ding et al. 2005). Characterizing viroid trafficking may help elucidate such cell-specific factors.

\section{Viroid RNA structural elements and host factors for symptom expression.}

Expression of viroid symptoms has long been recognized to result from interactions between viroid RNAs and cellular factors that lead to changes in development and physiology of an infected host (Diener 1999; Flores et al. 2004, 2005; Riesner and
Gross 1985; Semancik 1979; Tabler and Tsagris 2004). In light of recent discoveries of the many regulatory roles of noncoding RNAs in gene expression, development, and pathogen-host interactions, elucidating the mechanisms of viroid pathogenicity should contribute to a broad understanding of the mechanisms of RNA-based regulation of gene expression. Depending on viroid-host combinations, viroid infection can be symptomless or lethal to an infected plant. Furthermore, small sequence or structural variations in a viroid genome can have profound impacts on the degrees of symptom severity. Therefore, viroid pathogenicity offers an attractive experimental system in which to investigate the role of RNA sequence or structures in modulating cellular gene expression.

Viroid RNA structural elements for symptom expression. Most studies on the relationships between viroid RNA structures and symptom expression have been carried out with Pospiviroidae. Studies with CEVd (Visvader and Symons 1985, 1986) and PSTVd (Schnölzer et al. 1985) delineated a pathogenicity domain in which nucleotide variations were associated with different degrees of symptom severity. In general, symptom severity was not correlated with accumulation levels of viroid RNAs (Góra et al. 1996; Gruner et al. 1995; Rodio et al. 2006; Schnölzer et al. 1985; Visvader and Symons 1986), although exceptions have been reported (Sano et al. 1992; Visvader and Symons 1986). Therefore, symptom development largely results from specific molecular interactions between viroid nucleotide sequences or secondary or tertiary structures and cellular factors that lead to abnormal development. The mechanisms remain poorly understood. The early model, which indicated that the thermostability of the secondary structure in the pathogenicity domain dictates symptom severity (Schnölzer et al. 1985), was not supported by other data from PSTVd (Hammond 1992; Owens et al. 1995, 1996) and CEVd (Visvader and Symons 1985). In an alternative hypothesis, Owens and associates (1996) suggested that the different degrees of bending of the virulence-modulating (VM) region, within the pathogenicity domain, along the long axis of the PSTVd secondary structure may confer specific interactions with distinct host factors for symptom expression. The differences in the bending of the VM region of different PSTVd strains have been elegantly demonstrated by electrophoresis experiments (Schmitz and Riesner 1998). Identification of the cellular factors that interact with the VM region should lead to significant advances in our understanding of the molecular mechanisms underlying viroid pathogenicity.

There is compelling evidence that the pathogenicity domain is not the sole determinant of symptom development. Using heterologous chimeras between PSTVd and Tomato apical stunt viroid, Sano and associates (1992) showed that the left and right terminal domains also play a role in symptom expression. Reanwarakorn and Semancik (1998) showed that a region at the boundary of the central domain and variable domain is important for symptom expression of group II Citrus viroids, variants of HSVd. A PSTVd mutant carrying U257A substitution in the loop E caused flat-top and lethal symptoms in tomato (Qi and Ding 2003b). This mutant originally was recovered from transgenic tobacco plants expressing the cDNA of the intermediate strain of PSTVd (PSTVd ${ }^{\text {Int }}$ ) (Zhu et al. 2002). Interestingly, the U257A substitution has not been reported in any natural variants. Therefore, selection pressure during natural infection may not favor the preservation of this mutation. This mutation does not alter the loop E secondary (Qi and Ding 2003b) or tertiary structure (Zhong et al. 2006), the replication levels, or tissue tropism of PSTVd (Qi and Ding 2003b). Therefore, the loop E with A at position 257 apparently interacts with a distinct host factor or factors to cause the lethal symptoms on tomato. 
Investigating the sequence or structural motifs responsible for pathogenicity has led to exciting findings for the family Avsunviroidae. The hosts of ASBVd and PLMVd are woody species. The long period of time to elapse from inoculation to symptom expression, which can take weeks to months, presents practical challenges for mapping the viroid elements responsible for pathogenicity. Sequence comparisons among ASBVd clones isolated from green and bleached tissues of infected avocado suggest that a "U" insertion between nucleotides 115 and 118 may be responsible for bleaching symptoms (Schnell et al. 2001). By elegant sequence and mutational analyses, the peach calico (PC) symptom was shown to be associated with the presence of an extra 12- to 13-nt nucleotide sequence that folds into a hairpin in the left terminal loop (Malfitano et al. 2003; Rodio et al. 2006). Because this hairpin is absent from PLMVd strains that do not cause PC, it evidently is not essential for replication or movement. It is notable that the insertion occurs sporadically de novo and can be acquired or lost during infection. These observations raise the prospect of designing further experiments to test how this hairpin may function as a "separate unit" to interact with cellular factors to confer symptoms. However, the possibility that the presence of this hairpin facilitates the interaction of another part of the PLMVd genome or a replication intermediate with cellular factors to confer PC symptoms cannot be excluded.

Infection of chrysanthemum by CChMVd provides a practical system to more extensively and routinely investigate the RNA structural elements for symptom development, because infected plants can display disease symptoms 10 to 15 days postinoculation. Sequence or structural analyses of symptomatic and nonsymptomatic variants of CChMVd in conjunction with site-directed mutagenesis and bioassays identified tetraloop UUUC (nucleotides 82 to 85 ) as a major pathogenicity determinant (De La Peña et al. 1999). Conversion of this tetraloop to GAAA in natural variants or by mutagenesis renders the viroid nonsymptomatic. The replication levels of symptomatic and nonsymptomatic variants are similar, indicating that the viroid RNA titer is not a critical factor in symptom expression, similar to the situation reported for PSTVd. Thus, specific interactions between the viroid RNA motifs and cellular components appear to be the major cause of disease formation (De La Peña et al. 1999). Mutational and bioassay analyses demonstrated that the pathogenic motif is highly selected during in vivo evolution of viroid sequences. Furthermore, the stem structure capped by the tetraloop also is selected (De La Peña and Flores 2002).

Host factors for symptom expression. The host factors that serve at the primary targets of any viroid sequences or structures for symptom expression remain elusive. PSTVd infection causes phosphorylation of a protein kinase that is immunologically related to the mammalian interferon-induced, doublestranded RNA-activated protein kinase (Hiddinga et al. 1988; Langland et al. 1995). Further studies showed differential in vitro activation of the mammalian protein kinase P68 by PSTVd strains of different pathogenicity (Diener et al. 1993). The biological significance of this activation for viroid symptom expression remains to be understood. A $55-\mathrm{kDa}$ protein kinase viroid (PKV) with significant sequence homologies to cyclic nucleotide-dependent protein kinases is transcriptionally induced in PSTVd-infected plants (Hammond and Zhao 2000). Macroarrays revealed that many tomato genes are down- or upregulated in PSTVd-infected plants (Itaya et al. 2002). However, the data do not offer any clues about the genes that might play a primary role in symptom expression. The flat-top symptom caused by PSTVd ${ }^{\text {Int } U 257 A ~ i s ~ c o r r e l a t e d ~ w i t h ~ i n h i b i t e d ~ c e l l ~}$ growth and with downregulated expression of an expansin gene known to play a role in cell expansion (Qi and Ding 2003b). These changes also are likely to be secondary effects.
It is evident that host responses or host targets are complex and diverse. For instance, the PSTVd ${ }^{\text {Int }} \mathrm{U} 257 \mathrm{~A}$ is symptomless in tobacco but lethal in tomato (Qi and Ding 2003b; Zhu et al. 2002). Furthermore, Skoric and associates (2001) showed that temperature affects host responses, without altering viroid sequences or structures, for CEVd. Identifying the host components that the viroid RNAs interact with to elicit diseases will be one of the most important areas of future investigations. This not only is necessary for understanding the disease mechanisms of infectious RNAs, but also is likely to be important for gaining a general understanding of how a cellular RNA produced with abnormal sequences or structures could alter cellular metabolism.

\section{RNA silencing and viroid-host interactions.}

An emerging topic that links and will impact research on viroid replication, trafficking, and pathogenicity is the role of RNA silencing in these processes. RNA-mediated gene silencing is a powerful antiviral mechanism in plants and animals (Ding et al. 2004; Dunoyer and Voinnet 2005; Li and Ding 2005; Schütz and Sarnow 2006; Voinnet 2005) and plays crucial roles in regulating a wide range of developmental and growth processes (Bartel 2004; Baulcombe 2004; Carrington and Ambros 2003; Carthew 2006; Jones-Rhoades et al. 2006). RNA silencing involves several classes of 21- to 24-nt small RNAs as key mediators. These include microRNAs (miRNAs) and short interfering RNAs (siRNAs), which are produced by cleavage of structured precursor RNAs or cleavage of doublestranded RNAs (dsRNAs), respectively. RNase III dicer or dicer-like proteins (DCLs) and their associated proteins carry out the cleavage. The cleavage yields duplex miRNAs or siRNAs. One strand of the duplex is incorporated into the RNA-induced silencing complex (RISC) to guide degradation or translation inhibition of a target RNA, or into an RNAinduced initiator of transcriptional silencing complex (RITS) to guide DNA methylation-based chromatin modifications (Baulcombe 2004; Chan et al. 2004; Ekwall 2004; JonesRhoades et al. 2006; Matzke and Birchler 2005). As a counterdefense strategy, many viruses encode one or more proteins that function as silencing suppressors, which act by inhibiting various steps of the RNA silencing pathway (Roth et al. 2004).

Early work on viroid-host interactions led to the landmark discovery of RNA-directed DNA methylation (Wassenegger et al. 1994), which now is well established to be a fundamental mechanism of gene regulation and heterochromatin formation in multiple organisms (Chan et al. 2004; Matzke and Birchler 2005). Recent work has revealed, by Northern blots, small RNAs specific to viroid sequences in plants infected by a number of viroids from both families Pospiviroidae and Avsunviroidae. These include PSTVd (Itaya et al. 2001; Papaefthimiou et al 2001), PLMVd (Martínez de Alba et al. 2002), CChMVd (Martínez de Alba et al. 2002), ASBVd (Markarian et al. 2004), and CEVd (Markarian et al. 2004). These findings indicate that viroid RNAs can trigger RNA silencing. Recent work is beginning to address the mechanisms and implications of viroid-induced silencing.

Biogenesis of viroid small RNAs. How the viroid small RNAs are produced is not well understood. Landry and Perreault (2005) showed that a hairpin structure of PLMVd could serve as a substrate for DCL cleavage in WGE. Because PLMVd replicates in the chloroplasts, which are not yet known to possess an RNA-silencing system, how PLMVd small RNAs are produced in vivo remains to be elucidated. Recent work showed that small RNAs of PSTVd (srPSTVds) are derived predominantly from the highly structured PSTVd RNA (A. Itaya and B. Ding, unpublished data). The specific enzyme machinery for the generation of srPSTVds remains to 
be identified. The srPSTVd patterns and preliminary genetic experiments suggest the involvement of multiple DCL pathways (A. Itaya and B. Ding, unpublished data).

Viroid secondary structure confers resistance to RISC-mediated cleavage. Although the presence of viroid small RNAs suggested that RNA silencing is activated to inhibit viroid replication, accumulation of viroid genomic RNAs is rarely affected. On the contrary, higher accumulation levels of small RNAs is associated with higher accumulation of viroid genomic RNAs (Itaya et al. 2001). Recent work showed that replication of PSTVd in the protoplasts is resistant to silencing in the presence of dsPSTVd RNAs or synthetic siRNAs as silencing triggers (A. Itaya and B. Ding, unpublished data). This resistance can be attributed to the PSTVd secondary structure (Wang et al. 2004; A. Itaya and B. Ding, unpublished data), which is resistant to RISC-mediated cleavage (A. Itaya, unpublished data). Nuclear localization could provide another level of protection.

Viroid small RNAs and pathogenicity. The occurrence of viroid small RNAs has led to the proposition that these small RNAs may function like miRNAs or siRNAs to mediate silencing of host genes to cause symptoms (Flores et al. 2004, 2005; Markarian et al. 2004; Papaefthimiou et al. 2001; Wang et al. 2004). In line with this hypothesis, there is a positive correlation between the levels of small RNAs and symptom severity for PSTVd (Itaya et al. 2001) and ASBVd (Markarian et al. 2004). Moreover, symptom development is correlated with production of siRNAs in transgenic tomato expressing nonreplicating, dsPSTVd RNAs (Wang et al. 2004). It has been speculated that small RNA-guided silencing of host genes also may play a role in viral symptom expression (Dunoyer and Voinnet 2005). However, the correlation between viroid small RNA accumulation and symptom expression is not universal (Markarian et al. 2004; Papaefthimiou et al. 2001; Sano and Matsuura 2004). The observation that few srPSTVds are derived from PSTVd domains responsible for symptom expression raises the question of whether viroid small RNAs play a significant in pathogenicity (A. Itaya and B. Ding, unpublished data).

\section{Concluding remarks.}

RNA is rising rapidly to the central stage of current biology, fueled by the continuing discoveries of the diverse roles of noncoding RNAs in various biological processes. Studies on plant viruses and viroids have made many landmark contributions that enabled these discoveries. The important lesson, which is sometimes forgotten, is that plant pathogens are great, and often the most productive, tools to unravel some of the fundamental principles of life processes. Viroids already have made their distinct marks in the advancement of life sciences for the discoveries of hammerhead ribozymes (Hutchins et al. 1986) and RNA-directed DNA methylation (Wassenegger et al. 1994), to name a few. Here, we offer some perspectives on the utility of viroid-host interactions as model systems to continue investigating some basic biological problems.

Viroid RNAs are rich in structural motifs that likely are involved in the diverse biological functions necessary to establish infection. Therefore, viroids will allow investigation of the many aspects of RNA-protein interactions to achieve specific biological functions. The multi-functionality of some viroid motifs is of exceptional value for investigating the structurefunction relationships of RNAs in great details. For instance, the PSTVd loop E motif is involved in transcription (Zhong et al. 2006), processing (Baumstark et al. 1997), pathogenicity (Qi and Ding 2003b), and host adaptation (Qi and Ding 2002; Wassenegger et al. 1996; Zhu et al. 2002). In another example, the (+)-hammerhead ribozyme of CChMVd contains an extra " $A$ " in the highly conserved sequences. This " $A$ " is not required for self-cleavage in vitro but is necessary for infection. There- fore, the presence of this " $A$ " likely is important for a distinct function of the viroid RNA for infection (De la Peña and Flores 2001). Thus, to accomplish diverse functions, a viroid RNA motif may contain submotifs that interact with distinct cellular factors. Elucidating the underlying mechanisms will greatly expand our understanding of the capacity of a single RNA motif to regulate multiple biological processes. Such multifunctionality of a single RNA motif may be important for a wide range of RNA-based pathogens to expand their genome functions during evolution without increasing genome sizes.

Several viroid RNA motifs recur in different types of RNAs, with structures highly conserved. Well-known examples include the hammerhead ribozyme of Avsunviroidae and loop E of Pospiviroidae. The hammerhead ribozyme of the Avsunviroidae family is found in certain viral satellite RNAs (Forster and Symons 1987; Prody et al. 1986) and in cellular RNAs (Epstein and Gall 1987; Ferbeyre et al. 1998; Przybilski et al. 2005; Rojas et al. 2000; Zhang and Epstein 1996). The loop E of Pospiviroidae is a recurrent motif found in many RNAs, including $5 \mathrm{~S}, 16 \mathrm{~S}$, and $23 \mathrm{~S}$ rRNAs, group I and group II introns, bacterial RNase P, the hairpin ribozyme of satellite RNA of Tobacco ringspot virus (Leontis and Westhof 1998), and lysine riboswitches (Grundy et al. 2003; Sudarsan et al. 2003). Thus, elucidating the structure and function of viroid motifs can provide fundamental insights into the mechanisms of functions for a broad range of RNAs. Technically, viroid RNAs offer distinct advantages. For instance, mutational analysis is a powerful tool to define the specific functions of an RNA structural motif. This approach can be challenging for studying certain cellular RNAs because of the potential lethality of motif-disruptive mutations to an organism or because of the complexity of the folded RNA structures and sizes. Viroids offer an easier experimental system. The RNA is exogenous and the small size of viroid RNAs makes saturation mutagenesis feasible. Furthermore, in vitro and in vivo experimental approaches can be combined to investigate the effects of a mutation on viroid RNA function.

One of the ultimate goals of viroid research is to elucidate the cellular factors that replicate and traffic the viroid RNAs. Knowledge of these factors, together with knowledge of the specific functions of viroid RNA motifs, will be crucial to address the question of what minimal RNA sequences or structural motifs and protein factors are required to make a noncoding RNA infectious. Such knowledge also may help investigate the fundamental principles for the emergence of new RNAbased pathogens.

\section{ACKNOWLEDGMENTS}

This work was supported by grants from the National Science Foundation (IBN-0238412 and IOB-050515745). We thank X. Zhong for helpful discussions and comments and for critical reading of the manuscript. We express our gratitude to the anonymous reviewers for their insightful and valuable criticisms and suggestions. We apologize to colleagues whose work has not been cited due to space limitations.

\section{LITERATURE CITED}

Amari, K., Gómez, G., Myrta, A., Di Terlizzi, B., and Pallás, V. 2001. The molecular characterization of 16 new sequence variants of Hop stunt viroid reveals the existence of invariable regions and a conserved hammerhead-like structure on the viroid molecule. J. Gen. Virol. 82:953962.

Bartel, D. P. 2004. MicroRNAs: Genomics, biogenesis, mechanism, and function. Cell 116:281-297.

Baulcombe, D. 2004. RNA silencing in plants. Nature 431:356-363.

Baumstark T., and Riesner D. 1995. Only one of four possible secondary structures of the central conserved region of potato spindle tuber viroid is a substrate for processing in a potato nuclear extract. Nucleic Acids Res. 23:4246-4254.

Baumstark, T., Schröder, A. R., and Riesner, D. 1997. Viroid processing: 
Switch from cleavage to ligation is driven by a change from a tetraloop to a loop E conformation. EMBO (Eur. Mol. Biol. Organ.) J. 16:599-610.

Beaudry, D., Busiere, F., Lareau, F., Lessard, C., and Perreault, J. P. 1995. The RNA of both polarities of the peach latent mosaic viroid selfcleaves in vitro solely by single hammerhead structures. Nucleic Acids Res. 23:745-752.

Bonfiglioli, R. G., McFadden, G. I., and Symons, R. H. 1994. In situ hybridization localizes avocado sunblotch viroid on chloroplast thylakoid membranes and coconut cadang cadang viroid in the nucleus. Plant $\mathbf{J}$. 6:99-103.

Bonfiglioli, R. G., Webb, D. R., and Symons, R. H. 1996. Tissue and intracellular distribution of coconut cadang cadang viroid and citrus exocortis viroid determined by in situ hybridization and confocal laser scanning and transmission electron microscopy. Plant J. 9:457-465.

Branch, A. D., and Robertson, H. D. 1984. A replication cycle for viroids and other small infectious RNAs. Science 223:450-455.

Branch, A. D., Robertson, H. D., Greer, C., Gegenheimer, P., Peebles, C., and Abelson, J. 1982. Cell-free circularization of viroid progeny RNA by an RNA ligase from wheat germ. Science 217:1147-1149.

Branch, A. D., Benenfeld, B. J., and Robertson, H. D. 1985. Ultraviolet light-induced crosslinking reveals a unique region of local tertiary structure in potato spindle tuber viroid and HeLa 5S RNA. Proc. Natl. Acad. Sci. U.S.A. 82:6590-6594.

Bussière, F., Lehoux, J., Thompson, D. A., Skrzeczkowski, L. J., and Perreault, J. 1999. Subcellular localization and rolling circle replication of peach latent mosaic viroid: Hallmarks of group A viroids. J. Virol. 73:6353-6360.

Bussière, F., Ouellet, J., Côté, F., Levesque, D., and Perreault, J. P. 2000 Mapping in solution shows the peach latent mosaic viroid to possess a new pseudoknot in a complex, branched secondary structure. J. Virol. 74:2647-2654.

Candresse, T., Diener, T. O., and Owens, R. A. 1990. The role of the viroid central conserved region in cDNA infectivity. Virology 175:232-237.

Candresse, T., Góra-Sochacka, A., and Zagorski, W. 2001. Restoration of secondary hairpin II is associated with restoration of infectivity of a non-viable recombinant viroid. Virus Res. 75:29-34.

Carrington, J. C., and Ambros, V. 2003. Role of microRNAs in plant and animal development. Science 301:336-338.

Carthew, R. W. 2006. Gene regulation by microRNAs. Curr. Opin. Genet Dev. 16:203-208

Chan, S. W. L., Henderson, I. R., and Jacobsen, S. E. 2004. Gardening the genome: DNA methylation in Arabidopsis thaliana. Nat. Rev. Genet. 6:351-360.

Côté, F., and Perreault, J. P. 1997. Peach latent mosaic viroid is locked by a 2', 5'-phosphodiester bond produced by in vitro self-ligation. J. Mol. Biol. 273:533-543.

Côté, F., Levesque, D., and Perreault, J. P. 2001. Natural 2',5'-phosphodiester bonds found at the ligation sites of peach latent mosaic viroid. J. Virol. 75:19-25

Daròs, J. A., and Flores, R. 2002. A chloroplast protein binds a viroid RNA in vivo and facilitates its hammerhead-mediated self-cleavage. EMBO (Eur. Mol. Biol. Organ.) J. 21:749-759.

Daròs, J. A., Marcos, J. F., Hernandez, C., and Flores, R. 1994. Replication of avocado sunblotch viroid: Evidence for a symmetric pathway with two rolling circles and hammerhead ribozyme processing. Proc. Natl. Acad. Sci. U.S.A. 91:12813-12817.

De La Peña, M., and Flores, R. 2001. An extra nucleotide in the consensus catalytic core of a viroid hammerhead ribozyme: Implications for the design of more efficient ribozymes. J. Biol. Chem. 276:34586-34593.

De La Peña, M., and Flores, R. 2002. Chrysanthemum chlorotic mottle viroid RNA: Dissection of the pathogenicity determinant and comparative fitness of symptomatic and non-symptomatic variants. J. Mol. Biol. 321:411-421.

De La Peña, M., Navarro, B., and Flores, R. 1999. Mapping the molecular determinant of pathogenicity in a hammerhead viroid: A tetraloop within the in vivo branched RNA conformation. Proc. Natl. Acad. Sci. U.S.A. 96:9960-9965.

De La Peña, M., Gago, S., and Flores, R. 2003. Peripheral regions of natural hammerhead ribozymes greatly increase their self-cleavage activity. EMBO (Eur. Mol. Biol. Organ.) J. 22:5561-5570.

Delgado, S., Martínez de Alba, A. E., Hernandez, C., and Flores, R. 2005. A short double-stranded RNA motif of Peach latent mosaic viroid contains the initiation and the self-cleavage sites of both polarity strands. J. Virol. 79:12934-12943.

Diener, T. O. 1971. Potato spindle tuber "virus." IV. Replicating, low molecular weight RNA. Virology 45:411-428

Diener, T. O. 1986. Viroid processing: A model involving the central conserved region and hairpin I. Proc. Natl. Acad. Sci. U.S.A. 83:58-62.

Diener, T. O. 1999. Viroids and the nature of viroid diseases. Arch. Virol. Suppl. 15:203-220
Diener, T.O. 2003. Discovering viroids - a personal perspective. Nat. Rev. Microbiol. 1:75-80.

Diener, T. O., Hammond, R. W., Black, T., and Katze, M. G. 1993. Mechanism of viroid pathogenesis: Differential activation of the interferoninduced, double-stranded RNA-activated, M(r) 68,000 protein kinase by viroid strains of varying pathogenicity. Biochimie 75:533-538.

Dinant, S., Clark, A. M., Zhu, Y., Vilaine, F., Palauqui, J. C., Kusiak, C., and Thompson, G. A. 2003. Diversity of the superfamily of phloem lectins (phloem protein 2) in angiosperms. Plant Physiol. 131:114-128.

Ding, B., Kwon, M. O., Hammond, R., and Owens, R. 1997. Cell-to-cell movement of potato spindle tuber viroid. Plant J. 12:931-936.

Ding, B., Itaya, A., and Zhong, X. 2005. Viroid trafficking: A small RNA makes a big move. Curr. Opin. Plant Biol. 8:606-612.

Ding, S. W., Li, H., Lu, R., Li, F., and Li, W. X. 2004. RNA silencing: A conserved antiviral immunity of plants and animals. Virus Res. 102:109115

Dunoyer, P., and Voinnet, O. 2005. The complex interplay between plant viruses and host RNA-silencing pathways. Curr. Opin. Plant Biol. $8: 415-423$.

Ekwall, K. 2004. The RITS complex-A direct link between small RNA and heterochromatin. Mol. Cell 13:304-305.

Englert, M., and Beier, H. 2005. Plant tRNA ligases are multifunctional enzymes that have diverged in sequence and substrate specificity from RNA ligases of other phylogenetic origins. Nucleic Acids Res. 33:388399.

Epstein, L. M., and Gall, J. G. 1987. Self-cleaving transcripts of satellite DNA from the newt. Cell 48:535-543.

Fadda, Z., Daròs, J. A., Fagoaga, C., Flores, R., and Duran-Vila, N. 2003. Eggplant latent viroid, the candidate type species for a new genus within the family Avsunviroidae (hammerhead viroids). J. Virol 77:6528-6532.

Fels, A., Hu, K., and Riesner, D. 2001. Transcription of potato spindle tuber viroid by RNA polymerase II starts predominantly at two specific sites. Nucleic Acids Res. 29:4589-4597.

Ferbeyre, G., Smith, J. M., and Cedergren, R. 1998. Schistosome satellite DNA encodes active hammerhead ribozymes. Mol. Cell Biol. 18:38803888 .

Flores, R. 1989. Synthesis of RNAs specific to citrus exocortis viroid by a fraction rich in nuclei from infected Gynura aurantiaca: Examination of the nature of the products and solubilisation of the polymerase-template complex. J. Gen. Virol. 70:2695-2706.

Flores, R., and Semancik, J. S. 1982. Properties of a cell-free system for synthesis of citrus exocortis viroid. Proc. Natl. Acad. Sci. U.S.A. 79:6285-6288.

Flores, R., Delgado, S., Gas, M. E., Carbonell, A., Molina, D., Gago, S and De La Peña, M. 2004. Viroids: The minimal non-coding RNAs with autonomous replication. FEBS (Fed. Eur. Biochem. Soc.) Lett. 567:4248

Flores, R., Hernandez, C., Martínez de Alba, A. E., Daròs, J. A., and Di Serio, F. 2005. Viroids and Viroid-Host Interactions. Annu. Rev. Phytopathol. 43:117-139.

Forster, A. C., and Symons, R. H. 1987. Self-cleavage of plus and minus RNAs of a virusoid and a structural model for the active sites. Cell 49:211-220

Forster, A. C., Davies, C., Sheldon, C. C., Jeffries, A. C., and Symons, R. H. 1988. Self-cleaving viroid and newt RNAs may only be active as dimers. Nature 334:265-267.

Gago, S., De La Peña , M., and Flores, R. 2005. A kissing-loop interaction in a hammerhead viroid RNA critical for its in vitro folding and in vivo viability. RNA 11:1073-1083.

Gast, F. U., Kempe, D., Spieker, R. L., and Sänger, H. L. 1996. Secondary structure probing of potato spindle tuber viroid (PSTVd) and sequence comparison with other small pathogenic RNA replicons provides evidence for central non-canonical base-pairs, large A-rich loops, and a terminal branch. J. Mol. Biol. 262:652-670.

Golecki, B., Schulz, A., and Thompson, G. A. 1999. Translocation of structural $\mathrm{P}$ proteins in the phloem. Plant Cell 11:127-140.

Gómez, G., and Pallás, V. 2001. Identification of an in vitro ribonucleoprotein complex between a viroid RNA and a phloem protein from cucumber plants. Mol. Plant-Microbe Interact. 14:910-913.

Gómez, G., and Pallás, V. 2004. A long-distance translocatable phloem protein from cucumber forms a ribonucleoprotein complex in vivo with Hop stunt viroid RNA. J. Virol. 78:10104-10110.

Gómez, G., Torres, H., and Pallás, V. 2005. Identification of translocatable RNA-binding phloem proteins from melon, potential components of the long-distance RNA transport system. Plant J. 41:107-116.

Goodman, T. C., Nagel, L., Rappold, W., Klotz, G., and Riesner, D. 1984 Viroid replication: Equilibrium association constant and comparative activity measurements for the viroid-polymerase interaction. Nucleic Acids Res. 12:6231-6246. 
Góra, A., Candresse, T., and Zagorski, W. 1996. Use of intramolecular chimeras to map molecular determinants of symptom severity of potato spindle tuber viroid (PSTVd). Arch. Virol. 141:2045-2055.

Gozmanova, M., Denti, M. A., Minkov, I. N., Tsagris, M., and Tabler, M. 2003. Characterization of the RNA motif responsible for the specific interaction of potato spindle tuber viroid RNA (PSTVd) and the tomato protein Virp1. Nucleic Acids Res. 31:5534-5543.

Grill, L. K., and Semancik, J. S. 1978. RNA sequences complementary to citrus exocortis viroid in nucleic acid preparations from infected Gynura aurantiaca. Proc. Natl. Acad. Sci. U.S.A. 75:896-900.

Grundy, F. J., Lehman, S. C., and Henkin, T. M. 2003. The L box regulon: Lysine sensing by leader RNAs of bacterial lysine biosynthesis genes. Proc. Natl. Acad. Sci. U.S.A. 100:12057-12062.

Gruner, R., Fels, A., Qu, F., Zimmat, R., Steger, G., and Riesner, D. 1995. Interdependence of pathogenicity and replicability with potato spindle tuber viroid. Virology 209:60-69.

Hammond, R. W. 1992. Analysis of the virulence modulating region of potato spindle tuber viroid (PSTVd) by site-directed mutagenesis. Virology 187:654-662.

Hammond, R. W. 1994. Agrobacterium-mediated inoculation of PSTVd cDNAs onto tomato reveals the biological effect of apparently lethal mutations. Virology 201:36-45.

Hammond, R. W., Diener, T. O., and Owens, R. A. 1989. Infectivity of chimeric viroid transcripts reveals the presence of alternative processing sites in potato spindle tuber viroid. Virology 170:486-495.

Hammond, R. W., and Owens, R. A. 1987. Mutational analysis of potato spindle tuber viroid reveals complex relationships between structure and infectivity. Proc. Natl. Acad. Sci. U.S.A. 84:3967-3971.

Hammond, R. W., and Zhao, Y. 2000. Characterization of a tomato protein kinase gene induced by infection by Potato spindle tuber viroid. Mol. Plant-Microbe Interact. 13:903-910.

Harders, J., Lukacs, N., Robert-Nicoud, M., Jovin, T. M., and Riesner, D. 1989. Imaging of viroids in nuclei from tomato leaf tissue by in situ hybridization and confocal laser scanning microscopy. EMBO (Eur. Mol. Biol. Organ.) J. 8:3941-3949.

Hashimoto, J., and Machida, Y. 1985. The sequence in the potato spindle tuber viroid required for its cDNA to be infective. J. Gen. Appl. Microbiol. 31:551-561.

Haywood, V., Yu, T. S., Huang, N. C., and Lucas, W. J. 2005. Phloem long-distance trafficking of GIBBERELLIC ACID-INSENSITIVE RNA regulates leaf development. Plant J. 42:49-68.

Henco, K., Sänger, H. L., and Riesner, D. 1979. Fine structure melting of viroids as studied by kinetic methods. Nucleic Acids Res. 6:3041-3059.

Hernandez, C., and Flores, R. 1992. Plus and minus RNAs of peach latent mosaic viroid self-cleave in vitro via hammerhead structures. Proc. Natl. Acad. Sci. U.S.A. 89:3711-3715.

Hiddinga, H. J., Crum, C. J., Hu, J., and Roth, D. A. 1988. Viroid-induced phosphorylation of a host protein related to a dsRNA-dependent protein kinase. Science 241:451-453.

Hu, Y., Feldstein, P. A., Bottino, P. J., and Owens, R. A. 1996. Role of the variable domain in modulating potato spindle tuber viroid replication. Virology 219:45-56.

Hutchins, C. J., Rathjen, J. P., Forster, A. C., and Symons, R. H. 1986 Self-cleavage of plus and minus RNA transcripts of avocado sunblotch viroid. Nucleic Acids Res. 14:3627-3640.

Itaya, A., Folimonov, A., Matsuda, Y., Nelson, R. S., and Ding, B. 2001. Potato spindle tuber viroid as inducer of RNA silencing in infected tomato. Mol. Plant-Microbe Interact. 14:1332-1334.

Itaya, A., Matsuda, Y., Gonzales, R. A., Nelson, R. S., and Ding, B. 2002. Potato spindle tuber viroid strains of different pathogenicity induces and suppresses expression of common and unique genes in infected tomato. Mol. Plant-Microbe Interact. 15:990-999.

Jones-Rhoades, M. W., Bartel, D. P., and Bartel, B. 2006. MicroRNAs and their regulatory roles in plants. Annu. Rev. Plant Biol. 57:19-53.

Keese, P., and Symons, R. H. 1985. Domains in viroids: Evidence of intermolecular RNA rearrangements and their contribution to viroid evolution. Proc. Natl. Acad. Sci. U.S.A. 82:4582-4586.

Khvorova, A., Lescoute, A., Westhof, E., and Jayasena, S. D. 2003. Sequence elements outside the hammerhead ribozyme catalytic core enable intracellular activity. Nat. Struct. Biol. 10:708-712 (erratum in Nat. Struct. Biol. 10:872)

Kikuchi, Y., Tyc, K., Filipowicz, W., Sänger, H. L., and Gross, H. J. 1982. Circularization of linear viroid RNA via 2'-phosphomonoester, 3',5'phosphodiester bonds by a novel type of RNA ligase from wheat germ and Chlamydomonas. Nucleic Acids Res. 10:7521-7529.

Kolonko, N., Bannach, O., Aschermann, K., Hu, K. H., Moors, M., Schmitz, M., Steger, G., and Riesner, D. 2006. Transcription of potato spindle tuber viroid by RNA polymerase II starts in the left terminal loop. Virology 347:392-404.

Lafontaine, D., Beaudry, D., Marquis, P., and Perreault, J. P. 1995. Intra- and intermolecular nonenzymatic ligations occur within transcripts derived from the peach latent mosaic viroid. Virology 212:705-709.

Lai, M. M. 2005. RNA replication without RNA-dependent RNA polymerase : Surprises from hepatitis delta virus. J. Virol. 79:7951-7958.

Landry, P., and Perreault, J. P. 2005. Identification of a peach latent mosaic viroid hairpin able to act as a Dicer-like substrate. J. Virol. 79:65406543

Langland, J. O., Jin, S., Jacobs, B. L., and Roth, D. A. 1995. Identification of a plant-encoded analog of PKR, the mammalian double-stranded RNA-dependent protein kinase. Plant Physiol. 108:1259-1267.

Leontis, N. B., and Westhof, E. 1998. The 5S rRNA loop E: Chemical probing and phylogenetic data versus crystal structure. RNA 4:11341153.

Leontis, N. B., Stombaugh, J., and Westhof, E. 2002. The non-WatsonCrick base pairs and their associated isostericity matrices. Nucleic Acids Res. 30:3497-3531.

Li, H. W., and Ding, S. W. 2005. Antiviral silencing in animals. FEBS (Fed. Eur. Biochem. Soc.) Lett. 579:5965-5973.

Lima, M. I., Fonseca, M. E., Flores, R., and Kitajima, E. W. 1994. Detection of avocado sunblotch viroid in chloroplasts of avocado leaves by in situ hybridization. Arch. Virol. 138:385-390.

Liu, Y. H., and Symons, R. H. 1998. Specific RNA self-cleavage in coconut cadang cadang viroid: Potential for a role in rolling circle replication. RNA 4:418-429.

Loss, P., Schmitz, M., Steger, G., and Riesner, D. 1991. Formation of a thermodynamically metastable structure containing hairpin II is critical for infectivity of potato spindle tuber viroid RNA. EMBO (Eur. Mol. Biol. Organ.) J. 10:719-727.

Lucas, W. J. 2006. Plant viral movement proteins: Agents for cell-to-cell trafficking of viral genomes. Virology 344:169-184.

Malfitano, M., Di Serio, F., Covelli, L., Ragozzino, A., Hernandez, C., and Flores, R. 2003. Peach latent mosaic viroid variants inducing peach calico (extreme chlorosis) contain a characteristic insertion that is responsible for this symptomatology. Virology 313:492-501.

Maniataki, E., Martínez de Alba, A. E., Gesser, R. S., Tabler, M., and Tsagris, M. 2003. Viroid RNA systemic spread may depend on the interaction of a 71-nucleotide bulged hairpin with the host protein VirP1. RNA 9:346-354.

Markarian, N., Li, H. W., Ding, S. W., and Semancik, J. S. 2004. RNA silencing as related to viroid induced symptom expression. Arch. Virol. 149:397-406

Martínez de Alba, A. E., Flores, R., and Hernandez, C. 2002. Two chloroplastic viroids induce the accumulation of small RNAs associated with posttranscriptional gene silencing. J. Virol. 76:13094-13096.

Martínez de Alba, A. E., Sagesser, R., Tabler, M., and Tsagris, M. 2003. A bromodomain-containing protein from tomato specifically binds potato spindle tuber viroid RNA in vitro and in vivo. J. Virol. 77:9685-9694.

Matzke, M. A. and Birchler, J. A. 2005. RNAi-mediated pathways in the nucleus. Nat. Rev. Genet. 6:24-35.

Meshi, T., Ishikawa, M., Watanabe, Y., Yamaya, J., Okada, Y., Sano, T., and Shikata, E. 1985. The sequence necessary for the infectivity of hop stunt viroid cDNA. Mol. Gen. Genet. 200:199-206.

Mühlbach, H. P. and Sänger, H. L. 1979. Viroid replication is inhibited by alpha-amanitin. Nature 278:185-188.

Navarro, B., and Flores, R. 1997. Chrysanthemum chlorotic mottle viroid: Unusual structural properties of a subgroup of self-cleaving viroids with hammerhead ribozymes. Proc. Natl. Acad. Sci. U.S.A. 94:1126211267.

Navarro, J. A., and Flores. R. 2000. Characterization of the initiation sites of both polarity strands of a viroid RNA reveals a motif conserved in sequence and structure. EMBO (Eur. Mol. Biol. Organ.) J. 19:26622670.

Navarro, J. A., Daròs, J. A., and Flores, R. 1999. Complexes containing both polarity strands of avocado sunblotch viroid: Identification in chloroplasts and characterization. Virology 253:77-85.

Navarro, J. A., Vera, A., and Flores, R. 2000. A chloroplastic RNA polymerase resistant to tagetitoxin is involved in replication of avocado sunblotch viroid. Virology 268:218-225.

Owens, R. A., Hammond, R. W., Gardner, R. C., Kiefer, M. C., Thompsom, S. M., and Cress, D. E. 1986. Site-specific mutagenesis of potato spindle tuber viroid cDNA. Plant Mol. Biol. 6:179-192.

Owens, R. A., Thompson, S. M., and Steger, G. 1991. Effects of random mutagenesis upon potato spindle tuber viroid replication and symptom expression. Virology 185:18-31.

Owens, R. A., Chen, W., Hu, Y., and Hsu, Y. H. 1995. Suppression of potato spindle tuber viroid replication and symptom expression by mutations which stabilize the pathogenicity domain. Virology 208:554-564.

Owens, R. A., Steger, G., Hu, Y., Fels, A., Hammond, R. W., and Riesner, D. 1996. RNA structural features responsible for potato spindle tuber viroid pathogenicity. Virology 222:144-158. 
Owens, R. A., Blackburn, M., and Ding, B. 2001. Possible involvement of the phloem lectin in long-distance viroid movement. Mol. PlantMicrobe Interact. 14:905-909.

Palukaitis, P. 1987. Potato spindle tuber viroid: Investigation of the longdistance, intra-plant transport route. Virology 158:239-241.

Papaefthimiou, I., Hamilton, A., Denti, M., Baulcombe, D., Tsagris, M., and Tabler, M. 2001. Replicating potato spindle tuber viroid RNA is accompanied by short RNA fragments that are characteristic of posttranscriptional gene silencing. Nucleic Acids Res. 29:2395-2400.

Pelchat, M., and Perreault, J. P. 2004. Binding site of Escherichia coli RNA polymerase to an RNA promoter. Biochem. Biophys. Res. Commun. 319:636-642.

Pelchat, M., Grenier, C., and Perreault, J. P. 2002. Characterization of a viroid-derived RNA promoter for the DNA-dependent RNA polymerase from Escherichia coli. Biochemistry 41:6561-6571.

Prody, G. A., Bakos, J. T., Buzayan, J. M., Schneider, I. R., and Bruening, G. 1986. Autolytic processing of dimeric plant virus satellite RNA. Science 231:1577-1580.

Przybilski, R., Graf, S., Lescoute, A., Nellen, W., Westhof, E., Steger, G., and Hammann, C. 2005. Functional hammerhead ribozymes naturally encoded in the genome of Arabidopsis thaliana. Plant Cell 17:18771885

Qi, Y., and Ding, B. 2002. Replication of Potato spindle tuber viroid in cultured cells of tobacco and Nicotiana benthamiana: The role of specific nucleotides in determining replication levels for host adaptation. Virology 302:445-456.

Qi, Y., and Ding, B. 2003a. Differential subnuclear localization of RNA strands of opposite polarity derived from an autonomously replicating viroid. Plant Cell 15:2566-2577.

Qi, Y., and Ding, B. 2003b. Inhibition of cell growth and shoot development by a specific nucleotide sequence in a noncoding viroid RNA. Plant Cell 15:1360-1374.

Qi, Y., Pelissier, T., Itaya, A., Hunt, E., Wassenegger, M., and Ding, B. 2004. Direct role of a viroid RNA motif in mediating directional RNA trafficking across a specific cellular boundary. Plant Cell 16:1741-1752.

Qu, F., Heinrich, C., Loss, P., Steger, G., Tien, P., and Riesner, D. 1993. Multiple pathways of reversion in viroids for conservation of structural elements. EMBO (Eur. Mol. Biol. Organ.) J. 12:2129-2139.

Rackwitz, H. R., Rohde, W., and Sänger, H. L. 1981. DNA-dependent RNA polymerase II of plant origin transcribes viroid RNA into fulllength copies. Nature 291:297-301.

Reanwarakorn, K., and Semancik, J. S. 1998. Regulation of pathogenicity in hop stunt viroid-related group II citrus viroids. J. Gen. Virol. 79:3163-3171.

Riesner, D., and Gross, H. J. 1985. Viroids. Annu. Rev. Biochem. 54. 54:531-64:531-564

Riesner, D., Henco, K., Rokohl, U., Klotz, G., Kleinschmidt, A. K., Domdey, H., Jank, P., Gross, H. J., and Sänger, H. L. 1979. Structure and structure formation of viroids. J. Mol. Biol. 133:85-115.

Rivera-Bustamante, R. F., and Semancik, J. S. 1989. Properties of a viroidreplicating complex solubilized from nuclei. J. Gen. Virol. 70:27072716.

Robertson, H. D., Rosen, D. L., and Branch, A. D. 1985. Cell-free synthesis and processing of an infectious dimeric transcript of potato spindle tuber viroid RNA. Virology 145:441-447.

Rocheleau, L., and Pelchat, M. 2006. The subviral RNA database: A toolbox for viroids, the hepatitis delta virus and satellite RNAs research. BMC Microbiol. 6:24.

Rodio, M. E., Delgado, S., Flores, R., and Di Serio, F. 2006. Variants of Peach latent mosaic viroid inducing peach calico: Uneven distribution in infected plants and requirements of the insertion containing the pathogenicity determinant. J. Gen. Virol. 87:231-240.

Rojas, A. A., Vazquez-Tello, A., Ferbeyre, G., Venanzetti, F., Bachmann, L., Paquin, B., Sbordoni, V., and Cedergren, R. 2000. Hammerhead-mediated processing of satellite pDo500 family transcripts from Dolichopoda cave crickets. Nucleic Acids Res. 28:4037-4043.

Roth, B. M., Pruss, G. J., and Vance, V. B. 2004. Plant viral suppressors of RNA silencing. Virus Res. 102:97-108.

Sano, T., and Matsuura, Y. 2004. Accumulation of short interfering RNAs characteristics of RNA silencing precedes recovery of tomato plants from severe symptoms of Potato spindle tuber viroid infection. J. Gen. Plant Pathol. 70:50-53.

Sano, T., Candresse, T., Hammond, R. W., Diener, T. O., and Owens, R. A. 1992. Identification of multiple structural domains regulating viroid pathogenicity. Proc. Natl. Acad. Sci. U.S.A. 89:10104-10108.

Schindler, I. M., and Mühlbach, H. P. 1992. Involvement of nuclear DNAdependent RNA polymerases in potato spindle tuber viroid replication: A reevaluation. Plant Sci. 84:221-229.

Schmitz, A., and Riesner, D. 1998. Correlation between bending of the VM region and pathogenicity of different Potato spindle tuber viroid strains. RNA 4:1295-1303.

Schnell, R. J., Olano, C. T., and Kuhn, D. N. 2001. Detection of avocado sunblotch viroid variants using fluorescent single-strand conformation polymorphism analysis. Electrophoresis 22:427-432.

Schnölzer, M., Haas, B., Ramm, K., Hofmann, H., and Sänger, H. L. 1985. Correlation between structure and pathogenicity of potato spindle tuber viroid (PSTV). EMBO (Eur. Mol. Biol. Organ.) J. 4:2181-2190.

Scholthof, H. B. 2005. Plant virus transport: Motions of functional equivalence. Trends Plant Sci. 10:376-382.

Schrader, O., Baumstark, T., and Riesner, D. 2003. A mini-RNA containing the tetraloop, wobble-pair and loop E motifs of the central conserved region of potato spindle tuber viroid is processed into a minicircle. Nucleic Acids Res. 31:988-998.

Schröder, A. R., and Riesner, D. 2002. Detection and analysis of hairpin II, an essential metastable structural element in viroid replication intermediates. Nucleic Acids Res. 30:3349-3359.

Schumacher, J., Sänger, H. L., and Riesner, D. 1983. Subcellular localization of viroids in highly purified nuclei from tomato leaf tissue. EMBO (Eur. Mol. Biol. Organ.) J. 2:1549-1555.

Schütz, S., and Sarnow, P. 2006. Interaction of viruses with the mammalian RNA interference pathway. Virology 344:151-157.

Semancik, J. S. 1979. Small pathogenic RNA in plants-the viroids. Annu. Rev. Phytopathol. 17:461-484.

Semancik, J. S., and Harper, K. L. 1984. Optimal conditions for cell-free synthesis of citrus exocortis viroid and the question of specificity of RNA polymerase activity. Proc. Natl. Acad. Sci. U.S.A. 81:4429-4433.

Semancik, J. S., Tsuruda, D., Zaner, L., Geelen, J. L., and Weathers, J. G. 1976. Exocortis disease : Subcellular distribution of pathogenic (viroid) RNA. Virology 69:669-676.

Simon, A. E., Roossinck, M. J., and Havelda, Z. 2004. Plant virus satellite and defective interfering RNAs: New paradigms for a new century. Annu. Rev. Phytopathol. 42:415-437.

Skoric, D., Conerly, M., Szychowski, J. A., and Semancik, J. S. 2001. CEVd-induced symptom modification as a response to a host-specific temperature-sensitive reaction. Virology 280:115-123.

Spiesmacher, E., Mühlbach, H. P., Schonoelzer, M., Haas, B., and Sänger, H. L. 1983. Oligomeric forms of potato spindle tuber viroid (PSTV) and of its complementary RNA are present in nuclei isolated from viroid-infected potato cells. Biosci. Rep. 3:767-774.

Stern, D.S., Higgs, D.C., and Yang, J. 1997. Transcription and translation in chloroplasts. Trends Plant Sci. 2:308-315.

Sudarsan, N., Wickiser, J. K., Nakamura, S., Ebert, M. S., and Breaker, R. R. 2003. An mRNA structure in bacteria that controls gene expression by binding lysine. Genes Dev. 17:2688-2697.

Tabler, M., and Sänger, H. L. 1985. Infectivity studies on different potato spindle tuber viroid (PSTV) RNAs synthesized in vitro with the SP6 transcription system. EMBO (Eur. Mol. Biol. Organ.) J. 4:2191-2199.

Tabler, M., and Tsagris, M. 2004. Viroids: Petite RNA pathogens with distinguished talents. Trends Plant Sci. 9:339-348.

Tabler, M., Tzortzakaki, S., and Tsagris, M. 1992. Processing of linear longer-than-unit-length potato spindle tuber viroid RNAs into infectious monomeric circular molecules by a G-specific endoribonuclease. Virology 190:746-753

Takahashi, T., and Diener, T. O. 1975. Potato spindle tuber viroid. XIV. Replication in nuclei isolated from infected leaves. Virology 64:106114.

Taylor, J. M. 2003. Replication of human hepatitis delta virus: Recent developments. Trends Microbiol. 11:185-190.

Tsagris, M., Tabler, M., Mühlbach, H. P., and Sänger, H. L. 1987a. Linear oligomeric potato spindle tuber viroid (PSTV) RNAs are accurately processed in vitro to the monomeric circular viroid proper when incubated with a nuclear extract from healthy potato cells. EMBO (Eur. Mol. Biol. Organ.) J. 6:2173-2183.

Tsagris, M., Tabler, M., and Sänger, H. L. 1987b. Oligomeric potato spindle tuber viroid (PSTV) RNA does not process autocatalytically under conditions where other RNAs do. Virology 157:227-231.

Visvader, J., and Symons, R. H. 1985. Eleven new sequence variants of citrus exocortis viroid and the correlation of sequence with pathogenicity. Nucleic Acids Res. 13:2907-2920.

Visvader, J. E., and Symons, R. H. 1986. Replication of in vitro constructed viroid mutants: Location of the pathogenicity-modulating domain of citrus exocortis viroid. EMBO (Eur. Mol. Biol. Organ.) J. 5:2051-2055

Visvader, J. E., Forster, A. C., and Symons, R. H. 1985. Infectivity and in vitro mutagenesis of monomeric cDNA clones of citrus exocortis viroid indicates the site of processing of viroid precursors. Nucleic Acids Res. 13:5843-5856.

Voinnet, O. 2005. Induction and suppression of RNA silencing: Insights from viral infections. Nat. Rev. Genet. 6:206-220.

Wang, M. B., Bian, X. Y., Wu, L. M., Liu, L. X., Smith, N. A., Isenegger, 
D., Wu, R. M., Masuta, C., Vance, V. B., Watson, J. M., Rezaian, A. Dennis, E. S., and Waterhouse, P. M. 2004. On the role of RNA silencing in the pathogenicity and evolution of viroids and viral satellites. Proc. Natl. Acad. Sci. U.S.A. 101:3275-3280.

Warrilow, D., and Symons, R. H. 1999. Citrus exocortis viroid RNA is associated with the largest subunit of RNA polymerase II in tomato in vivo. Arch. Virol. 144:2367-2375.

Wassenegger, M., and Krczal, G. 2006. Nomenclature and functions of RNA-directed RNA polymerases. Trends Plant Sci. 11:142-151.

Wassenegger, M., Heimes, S., Riedel, L., and Sänger, H. L. 1994. RNAdirected de novo methylation of genomic sequences in plants. Cell 76:567-576

Wassenegger, M., Spieker, R. L., Thalmeir, S., Gast, F. U., Riedel, L., and Sänger, H. L. 1996. A single nucleotide substitution converts potato spindle tuber viroid (PSTVd) from a noninfectious to an infectious RNA for Nicotiana tabacum. Virology 226:191-197.

Woo, Y.-M., Itaya, A., Owens, R. A., Tang, L., Hammond, R. W., Chou, H.-C., Lai, M. M. C., and Ding, B. 1999. Characterization of nuclear import of potato spindle tuber viroid RNA in permeabilized protoplasts. Plant J. 17:627-635.

Yoshikawa, N., and Takahashi, T. 1986. Inhibition of hop stunt viroid rep- lication by $\alpha$-amanitin. Z. Pflanzenkrankh. Pflanzenschutz 93:62-71.

Zhang, Y., and Epstein, L. M. 1996. Cloning and characterization of extended hammerheads from a diverse set of caudate amphibians. Gene 172:183-190

Zhao, Y., Owens, R. A., and Hammond, R. W. 2001. Use of a vector based on Potato virus $\mathrm{X}$ in a whole plant assay to demonstrate nuclear targeting of Potato spindle tuber viroid. J. Gen. Virol. 82:1491-1497.

Zhong, X., Leontis, N. B., Qian, S., Itaya, A., Boris-Lawrie, K., and Ding, B. 2006. Tertiary structural and functional analyses of a viroid RNA motif by Isostericity Matrix and mutagenesis reveal its essential role in replication. J. Virol. 80:8566-8581.

Zhu, Y., Green, L., Y.-M., W., Owens, R., and Ding, B. 2001. Cellular basis of potato spindle tuber viroid systemic movement. Virology 279:69-77.

Zhu, Y., Qi, Y., Xun, Y., Owens, R., and Ding, B. 2002. Movement of potato spindle tuber viroid reveals regulatory points of phloem-mediated RNA traffic. Plant Physiol. 130:138-146.

\section{AUTHOR-RECOMMENDED INTERNET RESOURCE}

Subviral RNA database: subviral.med.uottawa.ca 